\title{
Phytochemicals and PI3K Inhibitors in Cancer-An Insight
}

\author{
Vasanti Suvarna $^{1 *}$, Manikanta Murahari ${ }^{2}$, Tabassum Khan ${ }^{1}$, Pramila Chaubey ${ }^{3}$ and \\ Preeti Sangave ${ }^{4}$
}

${ }^{1}$ Department of Pharmaceutical Chemistry and Quality Assurance, SVKM's Dr. Bhanuben Nanavati College of Pharmacy, Mumbai, India, ${ }^{2}$ Department of Pharmaceutical Chemistry, Faculty of Pharmacy, M.S Ramaiah University of Applied Sciences, Bangalore, India, ${ }^{3}$ Department of Pharmaceutics, SVKM's Dr. Bhanuben Nanavati College of Pharmacy, Mumbai, India, ${ }^{4}$ Department of Pharmaceutical Sciences, School of Pharmacy and Technology Management, SVKM's NMIMS,

Mumbai, India

OPEN ACCESS

Edited by:

Thomas Efferth,

Johannes Gutenberg-Universität

Mainz, Germany

Reviewed by:

Rajendra Karki,

St. Jude Children's Research Hospital,

United States

Linlin Lu,

International Institute for Translational

Chinese Medicine, China

${ }^{*}$ Correspondence:

Vasanti Suvarna

vasanti.suvarna@bncp.ac.in

Specialty section:

This article was submitted to

Ethnopharmacology,

a section of the journal

Frontiers in Pharmacology

Received: 26 September 2017 Accepted: 30 November 2017

Published: 14 December 2017

Citation:

Suvarna V, Murahari M, Khan T,

Chaubey $P$ and Sangave $P(2017)$

Phytochemicals and PI3K Inhibitors in

Cancer-An Insight.

Front. Pharmacol. 8:916.

doi: 10.3389/fphar.2017.00916
In today's world of modern medicine and novel therapies, cancer still remains to be one of the prime contributor to the death of people worldwide. The modern therapies improve condition of cancer patients and are effective in early stages of cancer but the advanced metastasized stage of cancer remains untreatable. Also most of the cancer therapies are expensive and are associated with adverse side effects. Thus, considering the current status of cancer treatment there is scope to search for efficient therapies which are cost-effective and are associated with lesser and milder side effects. Phytochemicals have been utilized for many decades to prevent and cure various ailments and current evidences indicate use of phytochemicals as an effective treatment for cancer. Hyperactivation of phosphoinositide 3-kinase (PI3K) signaling cascades is a common phenomenon in most types of cancers. Thus, natural substances targeting PI3K pathway can be of great therapeutic potential in the treatment of cancer patients. This chapter summarizes the updated research on plant-derived substances targeting PI3K pathway and the current status of their preclinical studies and clinical trials.

Keywords: cancer, clinical trials, phytochemicals, Mitogen-activated protein kinases (MAPK), Mammalian TORC pathway, phosphatidylinositol-4, 5-bisphosphate (PI3K)

\section{INTRODUCTION}

Cancer is the primary reason of mortality in developing countries and secondary cause of mortality in third world countries (Meybodi et al., 2017). According to most recent statistics of cancer prevalence and death worldwide provided by the International Agency for Research on Cancer 2012, there are about 14 million new annual incidences of cancer. This number is expected to upsurge to 22 million per year within successive two decades. Developing countries have $60 \%$ of the world's total cases of cancer and $70 \%$ of world's deaths due to cancer attributing to lack of accessibility to treatment and failure of early detection. This is increasing the economic and social burden due to cancer incidence in such countries. Thus, effective treatment and prevention of cancer is important as cancer continues to be a major health problem worldwide (Jiang and Liu, 2008).

For the past 30 years, natural and synthetic compounds have been the backbone for cancer chemotherapy (Mann, 2002). However, there are some shortcomings related to synthetic drugs such as associated toxic side effects which limit their use and also the stringent regulatory process which they need to pass before they come in the market. In contrast, natural compounds from dietary 
sources do not have such toxic side effects and thus they are more appealing than the synthetic compounds. Phytochemicals are the secondary plant metabolites such as triterpenoids, flavonoids, catechols, sulphated carbohydrates, tannins. The literature reveals several natural compounds present in plant extracts, herbs, vegetables, and fruits exhibit anticancer activity against numerous cancers. Also various phytoconstituents have proven to be associated with protective effect in cancer treatment (Michaud et al., 2000). Thus, phytochemicals attract more scientific research due to their wide acceptance and costeffectiveness. From the 1940 s to the early 2010 s, almost $70 \%$ of the anticancer drugs are non-synthetic and $50 \%$ of them being phytochemicals such as vinca alkaloids, taxanes, camptothecins which possess cytotoxic activity contributing to effective cancer treatment (Jiang and Liu, 2008). Figure 1 and Table 1 represents examples of various phytochemicals and their sources proven to have anticancer activity. These compounds have also shown anti-angiogenic effects. Further herbal extracts are investigated in order to identify molecules targeting different pathways of angiogenesis (Kadioglu et al., 2013).

Recently, it is established that many bioactive components modulate cell signaling pathways to mediate the anticancer effect, such as Mitogen-activated protein kinase (MAPK), Wnt and phosphatidylinositol 3-kinase (PI3K)/Akt pathways. This chapter focuses on different phytoconstituents acting on a PI3K signaling pathway that has been responsible for cancer prevention (Reddy et al., 2003). Lipid kinase PI3K exhibits a crucial role in cell cycle, programmed cell death, DNA repair, angiogenesis, autophagy, motility, and cellular metabolism (Cantley, 2002) (Figure 2). PI3K pathway is the most activated route in case of human cancer. Therefore, it is crucial to consider in target specific cancer treatment (Workman et al., 2006; Clarke and Workman, 2012). On activation of PI3Ks, phosphatidylinositol $(3,4)$-bisphosphate converts to phosphatidylinositol $(3,4,5)$ triphosphate and engage Akt to cell membrane (Okkenhaug and Vanhaesebroeck, 2003; Yap et al., 2008). Recruitment of Akt leads to conformational change along with Akt phosphorylation followed by its activation. PI3Ks channel signal from cell surface is carried toward cytoplasm by generation of second messengers, phosphorylated phosphatidylinositol which successively phosphorylate downstream substrate and in the end event in proliferation, cell survival, and promote normal cell growth (Cantley, 2002; Osaki et al., 2004; Hu et al., 2012; Akinleye et al., 2013; Burris, 2013). Also PI3K/Akt is found to show crosstalks with other pathways such as MAPK pathway that regulate cell survival or growth. Constitutive activation of PI3K is found in various types of cancers. Aberrant activation of PI3K signaling pathway aid tumor angiogenesis and carcinogenesis (Osaki et al., 2004; Samuels et al., 2004; Slomovitz and Coleman, 2012; Patel, 2013). Other genetic deviations which urge the PI3K pathway in cancer which comprises of gene amplification of PI3Ks, depletion of regulatory activity of PTEN and receptor tyrosine kinase mutation activation. Thus, PI3K is a crucial target for different cancer types and phytochemicals targeting PI3K can be a novel and promising therapy for cancer.

Nucleotide-binding domain, leucine rich repeat containing proteins (NLRs) are intracellular sensors of molecular patterns associated with damage or pathogen entry. It's been reported that NLRs play significant role in regulation of several functional process like inflammation, cell proliferation, cell death, tumourogenesis. Recent study identified that NLRC3 as negative modulator of PI3K-mTOR pathway in tumor suppressor function (Karki et al., 2016). To further investigate the underlying mechanism Rajendra Karki et al. studied on mouse model of colorectal cancer in wild type and $\mathrm{NLRC}^{+/--}$. Study suggests that NLRC3 negatively regulates the PI3K/mTOR signaling pathway which are crucial for cell proliferation and survival. Still the role of NLRC3 in other pathways to be explored. Further molecular insights of NLRC3 might benefit in the treatment and prevention of metabolic diseases and cancer (Karki et al., 2017).

\section{Role of PI3K in Cancer}

$\mathrm{PI} 3 \mathrm{~K}$ is the potential and druggable target for cancer therapy. Literature suggests that $\mathrm{PI} 3 \mathrm{~K}$ signaling pathway is activated in almost $30-50 \%$ of various human cancers. Based on the structure and specificity of substrates, PI3Ks have been divided into three classes. Most commonly studied are Class I and so far four isoforms of Class 1A PI3K have been identified and encoded as PI3KCA, PI3KCB, PI3KCD, and PI3KCG which catalyzes the phosphorylation of inositol ring at $3^{\prime}$ position. All the isoforms are mediated though GPCRs under the regulatory control of $\mathrm{p} 110 \alpha, \mathrm{p} 110 \beta$, and $\mathrm{p} 110 \gamma$. Multiple components of the PI3K signaling pathway are activated and mutated in human cancers. Activation of PI3K is linked to increased levels of PIP3 which further activates Akt pathway and leads to cellular progression, survival, and angiogenesis (Liu et al., 2009).

Currently around 50 drugs have been identified targeting $\mathrm{PI} 3 \mathrm{~K} / \mathrm{Akt} / \mathrm{mTOR}$ and many of them are under clinical investigation especially of Class 1 pan-PI3K inhibitors. For effective cancer therapy, PI3K inhibitors in combination with pathways targeting Akt, mTOR, RTKs (receptor tyrosine kinases), MAPK (mitogen activated protein kinase), EGFR (epidermal growth factor receptor), HER2 (human EGF receptor 2), DNA repair enzymes (Yap et al., 2015; Massacesi et al., 2016; Pons-Tostivint et al., 2017).

\section{GINGEROLS}

10-gingerol and 6-gingerol are obtained from Ginger (Zingiber officinale), they exhibit anticancer, (Ryu and Chung, 2015) antineuroinflammatory, (Ho et al., 2013) antioxidant, and antiinflammatory (Dugasani et al., 2010) activities. Zhang et al. assessed the anti-cancer effect of 10-gingerol (10-G) against HeLa cells. The apoptotic effect on cells did not show diverse attribute after $12 \mathrm{~h}$ of treatment with $10-\mathrm{G}$. As the exposure was extended apoptotic cell number was higher in the case of $10-\mathrm{G}$ than that of 5-FU (Zhang et al., 2017). Controlling of PI3K/Akt pathway signal transduction could be linked with the anti-cancer activities of $10-\mathrm{G}$. Therefore, this head to examine the change of survival pathway related proteins. Former studies suggested that 6-gingerol had no effect on the expressions of PI3K and p85 $\alpha$; but, PI3K regulated an increase in phosphorylation of Akt by 6-Gingerol (Park et al., 2006). The present study investigated $10-\mathrm{G}$ induced apoptosis by PI3K/Akt/AMPK/ mTOR signaling 

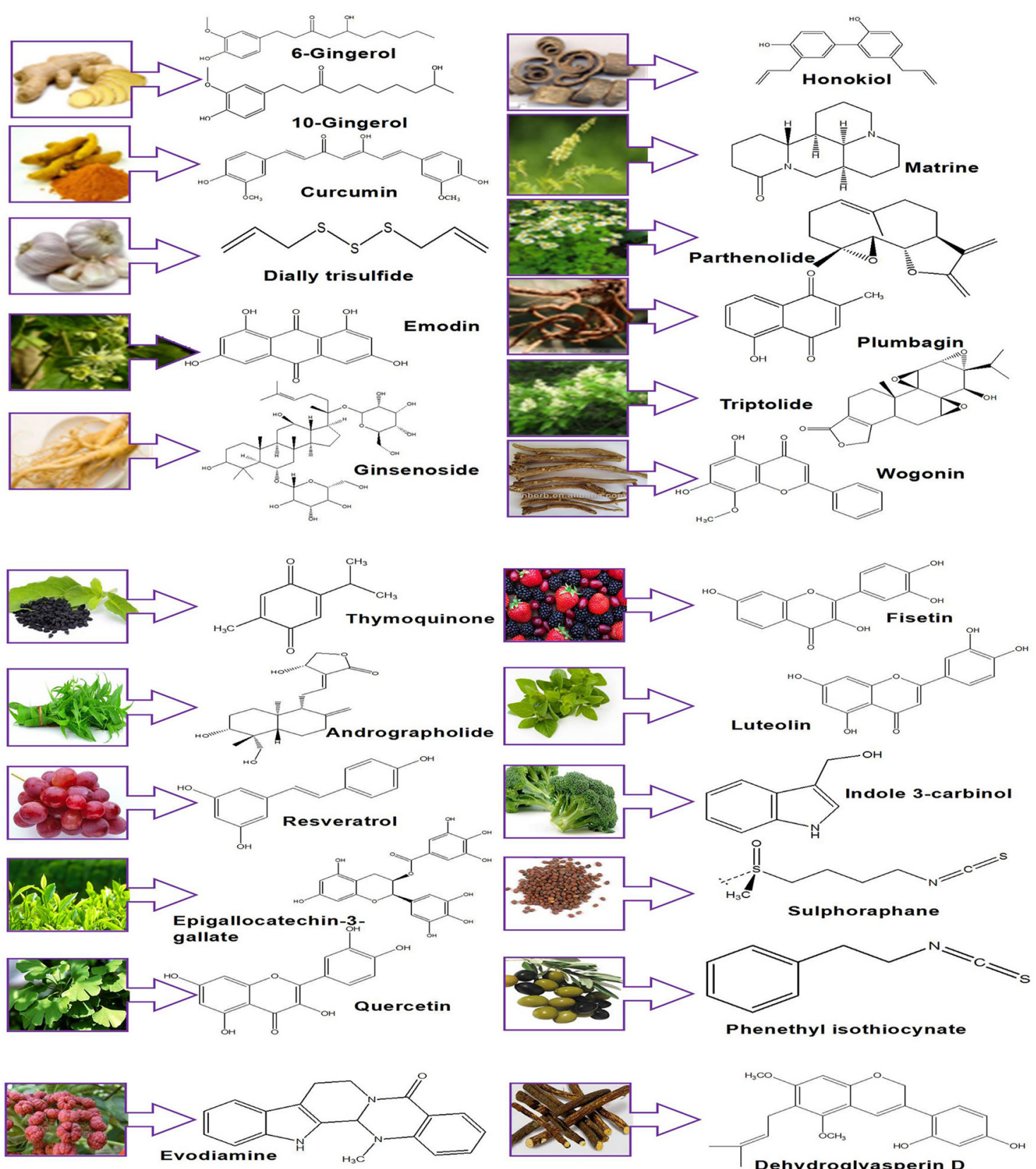

Sulphoraphane
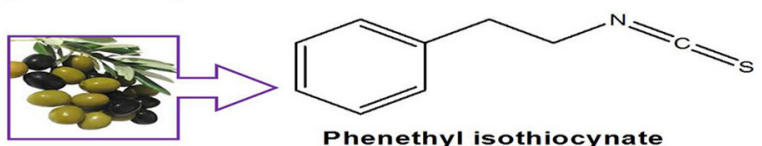

Phenethyl isothiocynate
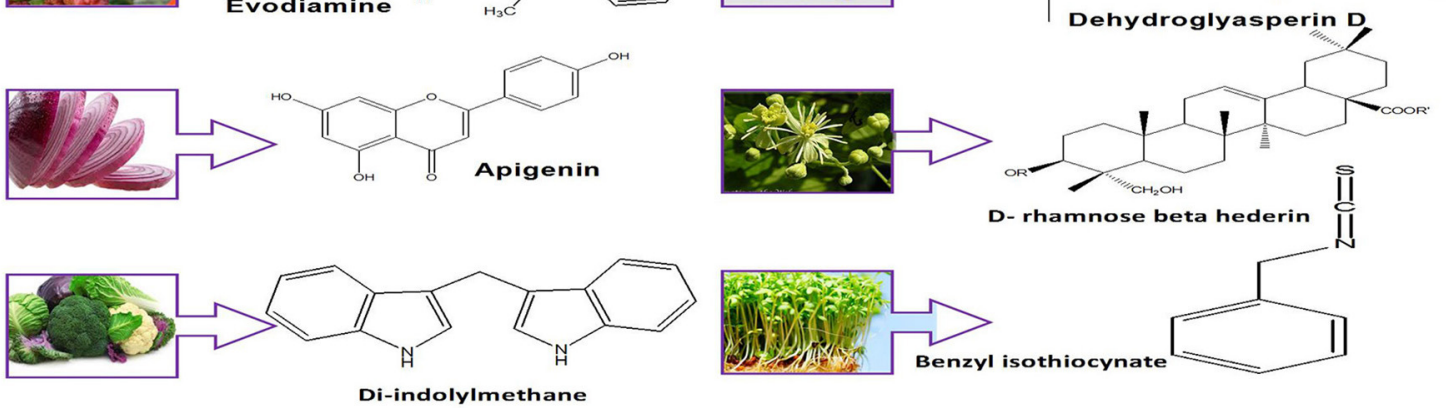

FIGURE 1 | Phytochemicals and their sources. 
TABLE 1 | Chemical and therapeutic profile of phytochemicals.

\begin{tabular}{|c|c|c|c|}
\hline Name of compounds & Chemical classification & Possible mechanism of action & Therapeutic uses \\
\hline Gingerols & Predominated phenols of ginger oil & Inhibition of PI3K/Akt pathway & $\begin{array}{l}\text { Anticancer, antineuroinflammatory, antioxidant, } \\
\text { anti-inflammatory, anti-cancer }\end{array}$ \\
\hline Curcumin & Flavonoid & $\begin{array}{l}\text { Inhibition of PI3K/Akt/mTOR } \\
\text { pathway }\end{array}$ & $\begin{array}{l}\text { Cardiovascular diseases, arthritis and inflammation, } \\
\text { breast, gastric, colon, prostate cancers, melanoma, } \\
\text { lymphoma, and leukemia }\end{array}$ \\
\hline Diallyl Trisulfide & Organosulfur compound & Inhibition of PI3K/Akt pathway & $\begin{array}{l}\text { Diabetes, cardiovascular disease, stimulate immune } \\
\text { system, induce apoptosis in colon, gastric, prostate, and } \\
\text { breast cancers }\end{array}$ \\
\hline Emodin & Anthraquinone derivative & Inhibition of PI3K/Akt pathway & Several human cancers, neuroprotective, anti-viral \\
\hline Ginsenoside RG3 & $\begin{array}{l}\text { Steroid glycosides and triterpene } \\
\text { saponins }\end{array}$ & Inhibition of PI3K/Akt pathway & Numerous types of cancers- ovarian, lung, melanoma \\
\hline D-Rhamnose $\beta$-hederin & Triterpenoid saponin & Inhibition of PI3K/Akt pathway & $\begin{array}{l}\text { Cardiovascular disease, neuroprotective, antioxidant, } \\
\text { anti-proliferative, neurodegenerative disease }\end{array}$ \\
\hline Honokiol & Neolignan biphenols & Inhibition of PI3K/Akt pathway & $\begin{array}{l}\text { Anti-thrombotic, anti-inflammatory, anti-oxidant, } \\
\text { anti-cancer- multiple myeloma, lung, and colorectal }\end{array}$ \\
\hline Matrine & Tetracyclic alkaloid & $\begin{array}{l}\text { Inhibition of PI3K/Akt/mTOR } \\
\text { pathway }\end{array}$ & $\begin{array}{l}\text { Anti-cancer, anti-inflammatory, anti-viral, anti-fibrotic, } \\
\text { anti-arrhythmic, immunosuppressive }\end{array}$ \\
\hline Parthenolide & Sesquiterpene lactone & Inhibition of PI3K/Akt pathway & $\begin{array}{l}\text { Arthritis, fever, head ache, anticancer- prostate, skin, } \\
\text { breast, bile duct, bowel, pancreas }\end{array}$ \\
\hline Plumbagin & Naphthoquinone & $\begin{array}{l}\text { Inhibition of PI3K/Akt/mTOR } \\
\text { pathway }\end{array}$ & $\begin{array}{l}\text { Anti-inflammatory, neuroprotective, hypolipidemic, } \\
\text { anticancer, anti-atherosclerotic, anti-fungal, antibacterial }\end{array}$ \\
\hline Triptolide & Diterpenoid triepoxide & Inhibition of PI3K/Akt pathway & $\begin{array}{l}\text { Arthritis, variety of cancers, anti-inflammatory, } \\
\text { immunosuppressive, anti-cystogenesis }\end{array}$ \\
\hline Wogonin & Flavone & Inhibition of PI3K/Akt pathway & $\begin{array}{l}\text { Anti-bacterial, antiviral, anti-oxidant, anti-inflammatory, } \\
\text { anti-cancer }\end{array}$ \\
\hline Thymoquinone & Benzoquinone of essential oil & Inhibition of PI3K/Akt pathway & $\begin{array}{l}\text { Bronchial headache, asthma, dysentery, gastrointestinal } \\
\text { problems }\end{array}$ \\
\hline Andrographolide & Labdane diterpenoid & Inhibition of PI3K/Akt pathway & $\begin{array}{l}\text { Upper respiratory tract infections, immunomodulatory, } \\
\text { anti-cancer }\end{array}$ \\
\hline Resveratrol & Natural polyphenol with stilbene & Inhibition of PI3K/Akt pathway & $\begin{array}{l}\text { Anti-viral, anti-inflammatory, anti-leukemic, } \\
\text { neuroprotective, chemoprotective, anti-oxidant }\end{array}$ \\
\hline Epigallocatechin-3-gallate & $\begin{array}{l}\text { Polyphenol, catechin, ester of } \\
\text { epigallocatechin and gallic acid }\end{array}$ & $\begin{array}{l}\text { Inhibition of PI3K/Akt/mTOR } \\
\text { pathway }\end{array}$ & $\begin{array}{l}\text { Cardiovascular disease, anti-cancer, anti-obesity, skin } \\
\text { protection from ionizing radiation }\end{array}$ \\
\hline Quercetin & Flavonoid & Inhibition of PI3K/Akt pathway & $\begin{array}{l}\text { Hay fever, diabetes, peptic ulcer, cataracts, asthma, } \\
\text { schizophrenia, gout inflammation, viral infections, } \\
\text { anti-cancer }\end{array}$ \\
\hline Fistein & Flavonoid & $\begin{array}{l}\text { Inhibition of PI3K/Akt/mTOR } \\
\text { pathway }\end{array}$ & Anti-oxidant, anti-inflammatory, anti-cancer \\
\hline Luteolin & Flavonoid & $\begin{array}{l}\text { Inhibition of PI3K/Akt/mTOR } \\
\text { pathway }\end{array}$ & Anti-cancer, anti-oxidant, anti-inflammatory \\
\hline Apigenin & Flavonoid & Inhibition of PI3K/Akt pathway & $\begin{array}{l}\text { Anti-inflammatory, sedative, numerous cancers- } \\
\text { prostate, melanoma, colon, and breast }\end{array}$ \\
\hline Indole-3-carbinol & Breakdown product of glucosinolate & Inhibition of PI3K/Akt pathway & $\begin{array}{l}\text { Numerous cancer types- breast, colon, thyroid, gastric, } \\
\text { prostate and mesothelioma }\end{array}$ \\
\hline Di-indolylmethane & $\begin{array}{l}\text { Derived product from digestion of } \\
\text { indole-3-carbinol }\end{array}$ & Inhibition of PI3K pathway & Anti-cancer \\
\hline Sulforaphane & $\begin{array}{l}\text { Organosulfur compound with } \\
\text { isothiocyanate group }\end{array}$ & Inhibition of PI3K/Akt pathway & Anti-cancer and anti-viral \\
\hline Phenethyl isothiocyanate & Isothiocyanate derivative & $\begin{array}{l}\text { Inhibition of PI3K/Akt/mTOR } \\
\text { pathway }\end{array}$ & Numerous cancers \\
\hline Benzyl isothiocyanate & Isothiocyanate derivative & Inhibition of PI3K/Akt pathway & Anti-cancer \\
\hline Dehydroglyasperin D & Prenyl flavonoid & Inhibition of PI3K pathway & $\begin{array}{l}\text { Anti-obesity, aldose reductase inhibition, anti-cancer, } \\
\text { anti-oxidant }\end{array}$ \\
\hline Evodiamine & Quinolone alkaloid & Inhibition of PI3K/Akt pathway & Anti-nociceptive, anti-anoxia and vasorelaxant \\
\hline Piceatannol & Natural analog of Resveratrol & Inhibition of PI3K pathway & $\begin{array}{l}\text { Anti-cancer, anti-inflammatory, atherosclerosis, } \\
\text { hypercholesterolemia, angiogenesis }\end{array}$ \\
\hline Ellagic acid & Polyphenol & $\begin{array}{l}\text { Inhibition of PI3K/Akt/mTOR } \\
\text { pathway }\end{array}$ & Anti-bacterial, anti-viral, anti-cancer \\
\hline
\end{tabular}




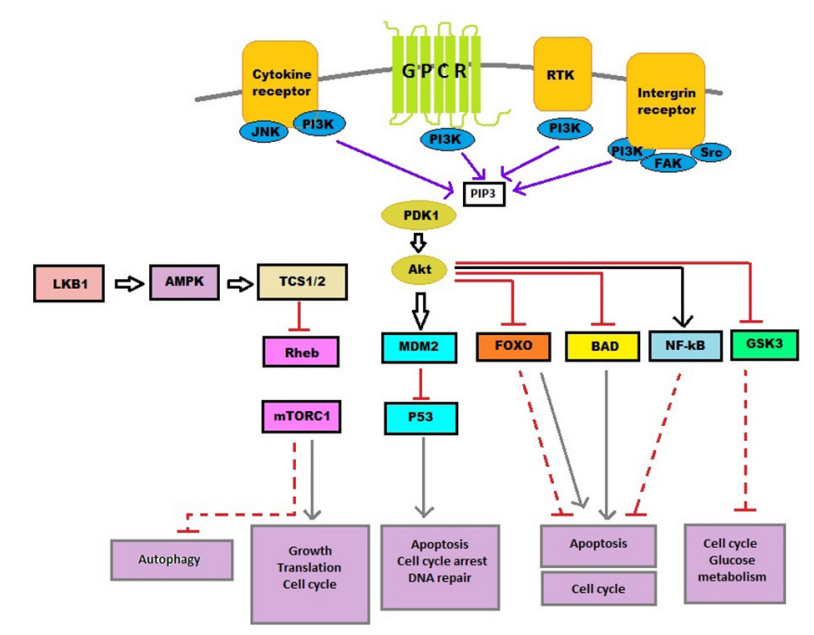

FIGURE 2 | PI3K signaling pathway. Cytokine, growth factor (RKT), hormones and intergrins are prime extra-cellular signals, which tend to transmit via suited pathways to control various cellular processes, like autophagy, DNA repair, cell cycle, angiogenesis, motility, angiogenesis, and senescence. BAD, Bcl-2-associated death promoter; FOXO, Forkhead box protein O; GPCR, G protein coupled receptors; GSK3, Glycogen synthase kinase 3; JNK, c-Jun N-terminal kinases; LKB1, Liver kinase B1; MDM2, Mouse double minute 2 homolog; mTOR C1, Mammalian target of rapamycin complex 1; NF-kB, Nuclear factor kappa-light-chain-enhancer of activated B cells; PDK1, Pyruvate dehydrogenase lipoamide kinase isozyme 1; PI3K, Phosphatidylinositide 3-kinases; PIP3, Phosphatidylinositol (3,4,5)-triphosphate; RHEB, Ras homolog enriched in brain; RTK, Receptor tyrosine kinase; TCS1/2, Two-component signal transduction protein 1/2.

pathways in HeLa cells which were confirmed by significant inhibition of PI3K phosphorylation. Overall results showed that 10-G triggered mTOR-mediated cell apoptosis by inhibiting PI3K/Akt and activating AMPK to induce mTOR-arbitrated cell apoptosis in HeLa cells (Zhang et al., 2017).

Weng et al. studied the molecular mechanism of 6-gingerol and 6-shogaol against hepatocarcinoma cells (HCC). In order to assess the inhibition and the primary molecular mechanism, the transition and translation of matrix metalloproteinases (MMP) and urokinase-type plasminogen activator (uPA), was studied. PI3K pathway inflects MMP expression. Western blots densitometric analyses revealed $\geq 10 \mu \mathrm{M}$ 6-Gingerol and $\geq 2.5 \mu \mathrm{M}$ 6-shogaol concentrations, notably repressed the phosphorylation of MAPK and PI3K/Akt signaling along with the activation of NF- $\kappa$ B, and translocation of NF- $\kappa$ B and STAT3 (Huynh, 2010). Thus, it was postulated that the target proteins which tend to regulate 6-gingerol and 6-shogaol-mediated inactivation of invasion and metastasis might likewise prevent angiogenesis in HCC (Weng et al., 2012).

\section{CURCUMIN}

Curcumin (1E,6E)-1,7-bis(4-hydroxy-3-methoxyphenyl)hepta1,6-diene-3,5-dione is a flavonoid isolated from rhizome of Curcuma longa (Minami et al., 2009). It is also used in cardiovascular disease, arthritis, and inflammation, breast cancer, gastric cancer, colon cancer, melanoma, prostate cancer, lymphoma, and leukemia (Shehzad et al., 2013).

Jiao et al. assessed the effect of curcumin in lung cancer, as the possible mechanism of curcumin in epithelial-mesenchymal transition (EMT) and angiogenesis was not known. As EMT and angiogenesis appear as two crucial events in cancer development. $\mathrm{HGF} / \mathrm{c}-\mathrm{Met}$ pathway is important for invasive growth. The involvement of PI3K pathway with activated c-Met intensifies PI3K activity (Eder et al., 2009). In lung cancer other than PI3K pathway, Akt/mTOR signaling pathway also exhibits a crucial role in modulation of EMT, cell growth, cell survival, and cell cycle. In this study, it was revealed that curcumin inhibited HGF induced EMT via inhibition of c-Met activation and PI3K/Akt/mTOR signaling pathway displaying anticancer effect of curcumin (Jiao et al., 2016).

\section{DIALLYL TRISULFIDE}

Diallyl trisulfide 3-(prop-2-enyltrisulfanyl) prop-1-ene is a main active compound isolated from Garlic (Allium sativum). It is used in diabetes, cardiovascular disease, to stimulate the immune system and against infections. Also, it has potent anticancer property, (Fleischauer et al., 2000; Hsing et al., 2002) induces apoptosis in colon, gastric, prostate, and breast cancer (ChandraKuntal and Singh, 2010; Zhang et al., 2015).

Wang et al. (2016) evaluated Diallyl trisulfide (DATS) induced apoptosis in MG63 and MNNG/HOS cell lines. The cells were evaluated with various concentration of DATS for $48 \mathrm{~h}$, whereas in some groups the cell lines were previously treated with $\mathrm{N}$-acetylcysteine (NAC) and then co-treated with DATS. The apoptosis effect was evaluated by western blotting technique. DATS showed an apoptotic behavior due to inactivation of PI3K/Akt pathway, which was reliant on ROS (Reactive Oxygen Species) generation which was highlighted by NAC treatment. Study concluded that antiproliferative and cytotoxic effect in human osteosarcoma cells (HOS) due to a positive correlation between ROS and PI3K/Akt signaling pathway in addition to the mitochondrial event leading to apoptosis. Also, it showed an increase in intracellular ROS level in addition to MG63 and MNNG/HOS G0/G1 phase cell cycle arrest and cell apoptosis which displays a great capability of diallyl trisulfide as an anticancer agent.

\section{EMODIN}

Emodin (1,3,8-trihydroxy-6-methylanthraquinone) is an anthraquinone existing in various herbs like Rheum Officinale, Semen Cassia, Polygonum multiflorum, and Polygonum cuspidatum.

Upregulation of PI3K pathway associated with tumors along with PI3K pathway activation leads to protein kinase B (Akt) phosphorylation (Bartholomeusz and Gonzalez-Angulo, 2012). Akt overexpression is found in many human cancers, where the active Akt promotes resistance to chemo- and radiotherapy (Courtney et al., 2010). Thus, PI3K/Akt pathways inhibition improves response to tumor cells (Yi et al., 2013). ChunGuang et al. (2010) evaluated the anti-apoptotic effect of 


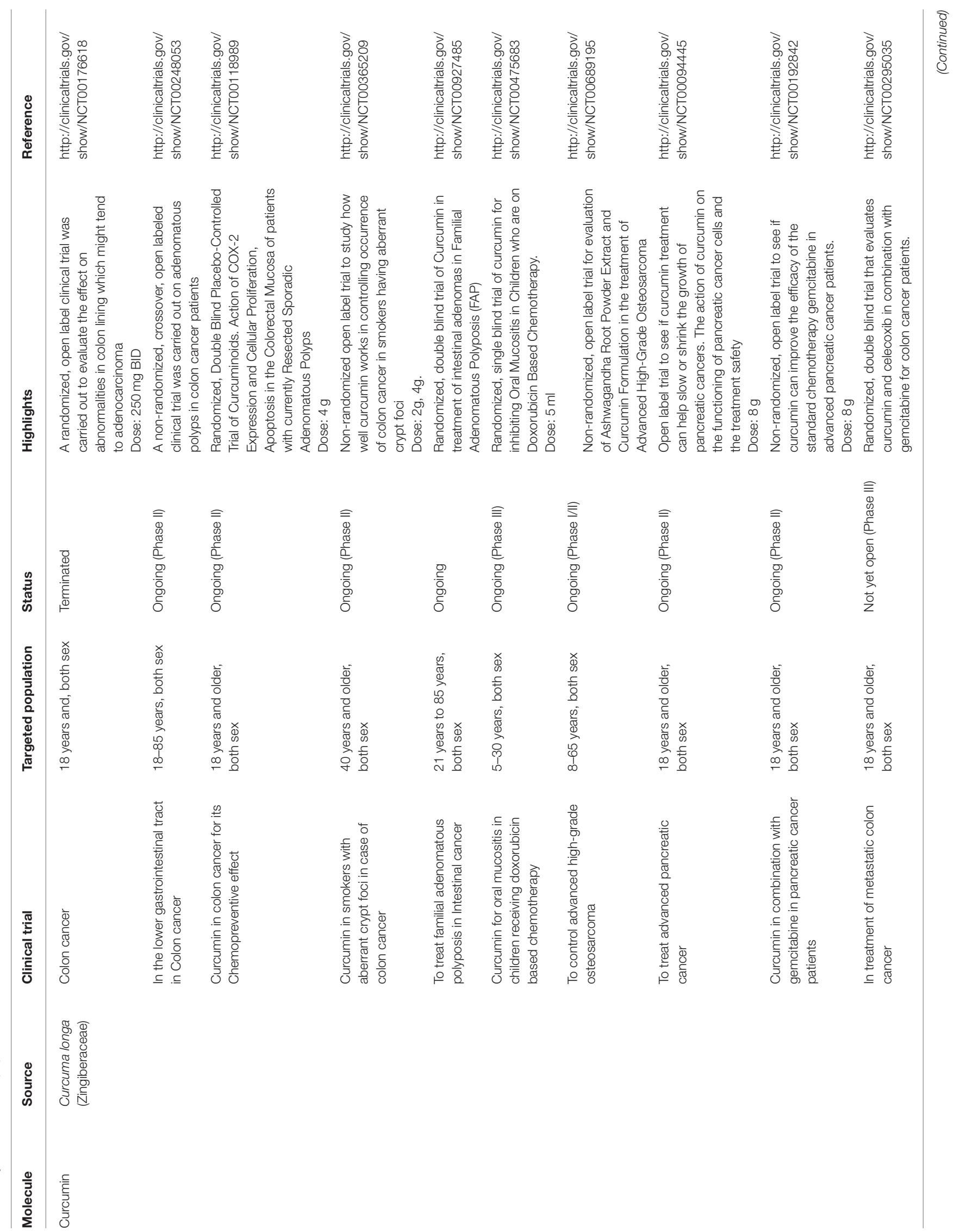




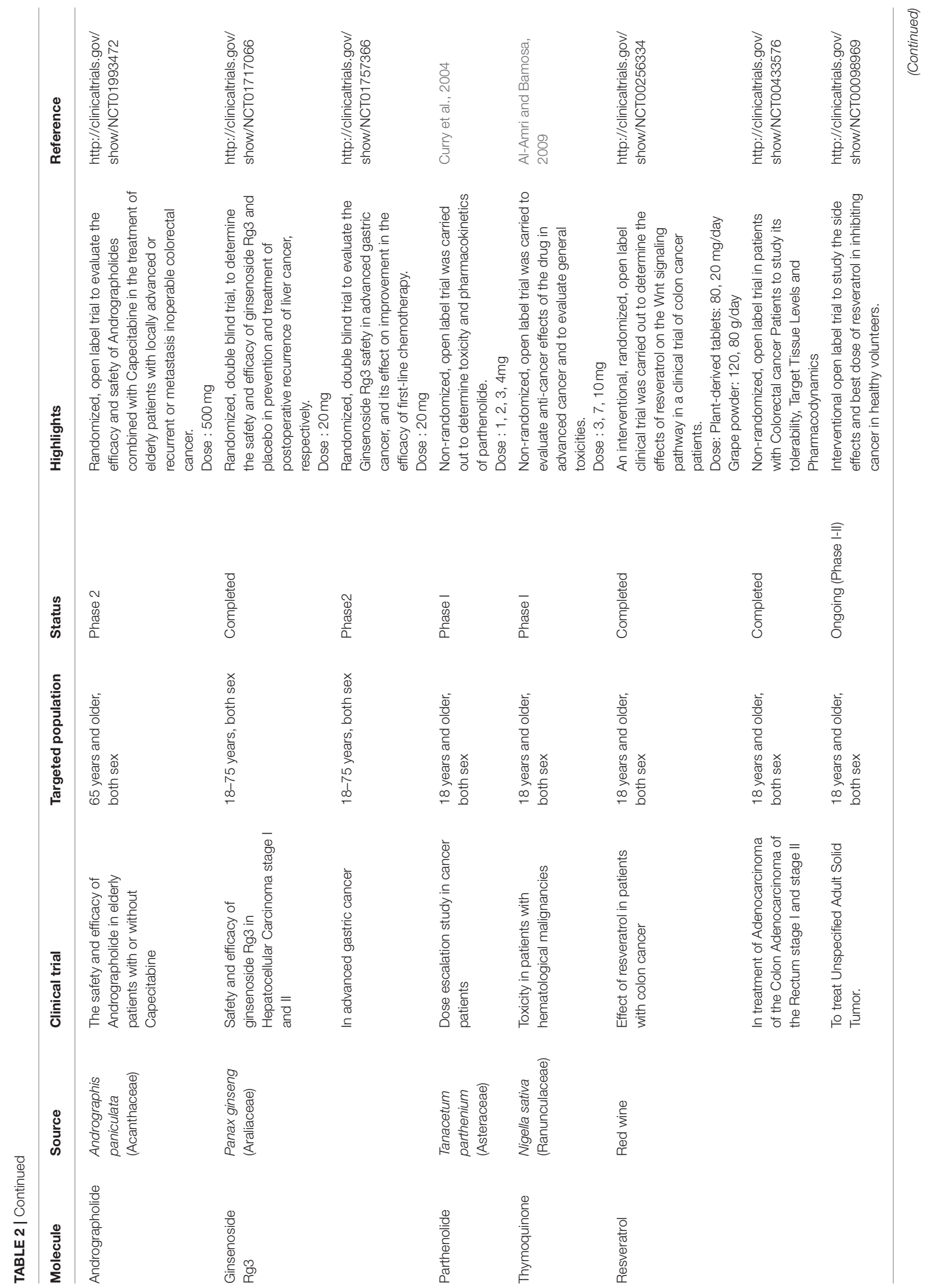




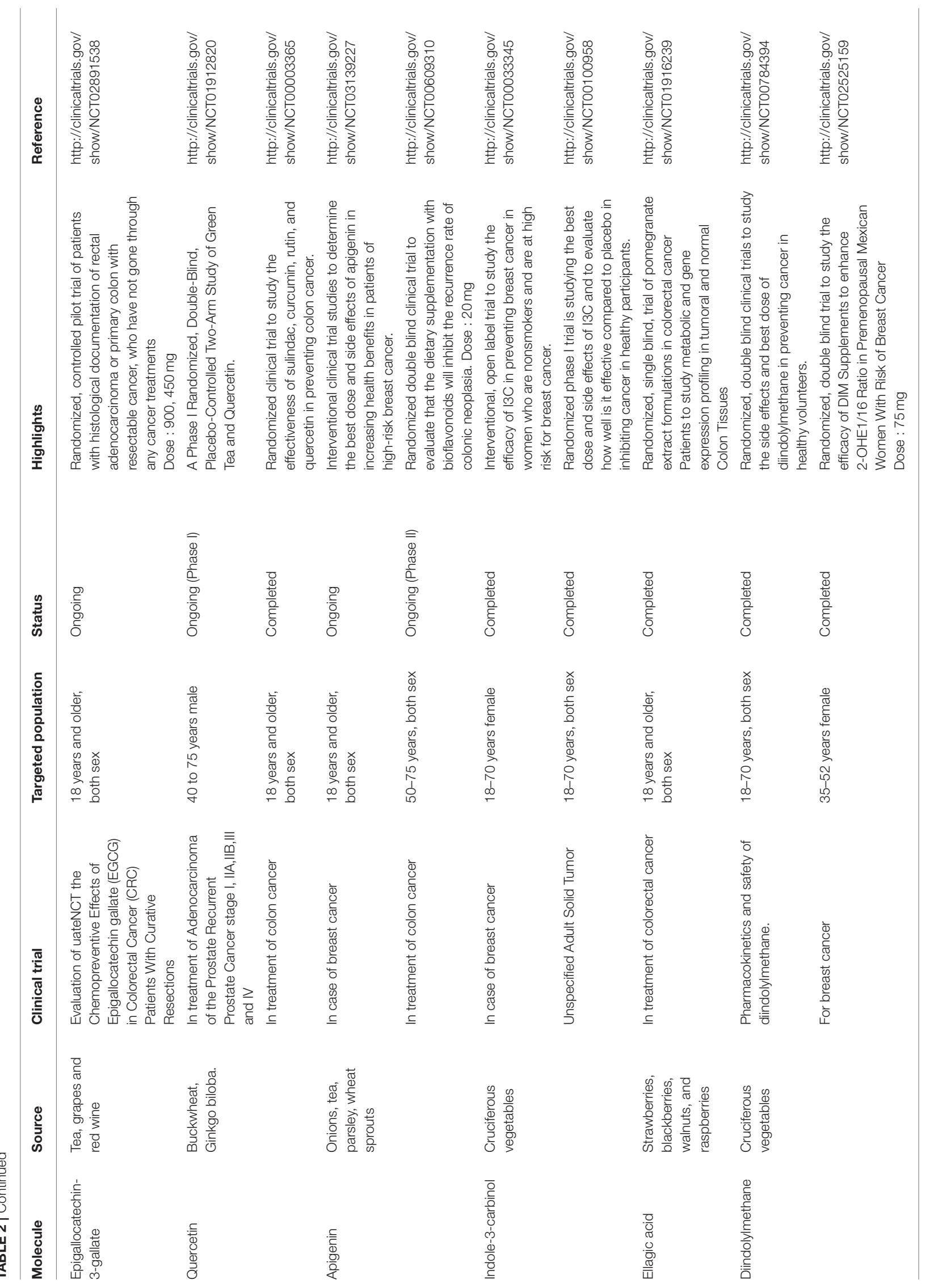


emodin on Human Chronic Myelocytic Leukemia K562 Cell Lines. Treatment of these cell lines with emodin showed downregulation of Akt kinase activity. The results suggested that emodin instigated apoptosis via inhibition of PI3K/Akt level, along with upregulation of (Phosphatase and tensin homolog) PTEN.

Cui et al. studied the molecular mechanism of emodin for its chemoprotective activity on HepG2 cells. Emodin treatment instigated apoptosis, in turn resulted in inhibition of PI3K/Akt and ERK (Nakanishi et al., 2005; Cui et al., 2016). Activation of ERK pathway elicited PI3K/Akt pathways activation, possibly by the disappearance of feedback inhibition. Thus, it was concluded Emodin-induced apoptosis resulted in inhibition of PI3K/Akt pathway and activation of p38 mediated through initiation of mitochondrial pathway (Saini et al., 2013).

\section{GINSENOSIDE RG3}

Ginsenoside Rg3 (2S,3R,4S,5S,6R)-2-[(2R,3R,4S,5S,6R)-4,5dihydroxy-2-[[(3S, 5R, 8R,9R, 10R,12R,13R,14R,17S)-12hydroxy-17-[(2S)-2-hydroxy-6-methyl-hept-5-en-2-yl]-4,4, 8,10, 14-pentamethyl-2,3,5,6,7,9,11,12,13,15,16,17-dodecahydro- $1 \mathrm{H}$ cyclopenta[a]phenanthren-3-yl]oxy]-6-(hydroxymethyl)oxan3-yl]oxy-6-(hydroxyl methyl)oxane-3,4,5-triol is obtained from red Panax ginseng. The herb possesses anti-proliferative activity against numerous types of cancer such as ovarian, lung and melanoma (Koo et al., 2007; Wang et al., 2007) and 20(s)ginsenoside $\mathrm{Rg} 3$ caused inhibition of varied cancers via inductive effects on several signaling pathways (Iishi et al., 1997; Keum et al., 2003; Lee et al., 2009).

Wang et al. studied the effect of 20(s)-ginsenoside Rg3 on HO-8910 cell lines. These cells were treated with various concentrations of 20(s)-ginsenoside $\mathrm{Rg} 3$. Several pieces of evidence suggested that HO-8910 cells propose deregulation of PI3K/Akt pathway, on their treatment with various concentrations of 20(s)-ginsenoside Rg3. (Kar et al., 2012; Wang et al., 2014). It was concluded that treatment with 20(s)-ginsenoside Rg3 resulted in down-regulation of PI3K/Akt pathway, activation of caspase-3 and -9 and inhibition of apoptosis protein (IAP) family proteins which play a significant part in apoptosis.

\section{D-RHAMNOSE $\beta$-HEDERIN}

D-Rhamnose $\beta$-Hederin (DR $\beta \mathrm{H}) \quad(3 \beta \quad[(\alpha$ Larabinopyranosyl) oxy] olean-12-en-28-oic acid) (DR $\beta \mathrm{H})$, is a triterpenoid saponin isolated from a traditional antitumor Chinese herb, Clematis ganpiniana (Ding et al., 2009).

Cheng et al. (2014) evaluated the apoptotic activity of D Rhamnose $\beta$-Hederin $(\mathrm{DR} \beta \mathrm{H})$ from C. ganpiniana on various breast cancer cells. MCF7 and MDAMB231 were treated with $(\mathrm{DR} \beta \mathrm{H})$. Western blotting technique disclosed suppression in the p-PI3K expression following treatment of MCF 7 and MDAMB231 with $\mathrm{DR} \beta \mathrm{H}$ in a time-dependent manner with sustained effect for $48 \mathrm{~h}$ (Calleja et al., 2009). Thus, it was concluded DR $\beta \mathrm{H}$ exerted an apoptotic effect through inhibition of PI3K/Akt pathway.

\section{HONOKIOL}

Honokiol 2-(4-hydroxy-3-prop-2-enylphenyl)-4-prop-2enylphenol is a phytochemical present in Magnolia Officinalis extract. It possesses anti-thrombotic (Zhang et al., 2007), antiinflammatory (Liou et al., 2003), anti-oxidant effect (Lo et al., 1994) along with anti-cancer activity in multiple myeloma (Battle et al., 2005; Ishitsuka et al., 2005), lung, and colorectal cancer cells (Yang et al., 2002; Wang et al., 2004).

Liu et al. verified the influence of honokiol on various breast cancer cell lines individually in estrogen receptor negative and positive cell lines in addition to cell lines resistant to tamoxifen resistant and Adriamycin resistant. PI3K/Akt/mTOR signaling pathway was shown to lead to anti-estrogen therapy resistance in cell lines of breast cancer (Clark et al., 2002; Normanno et al., 2005; Nahta et al., 2006). Also alterations from G0/1-phase to Sphase of the cell cycle were regulated by mTOR a downstream mediator of PI3K/Akt pathway (Altomare and Testa, 2005). Based on the observations of the study it was hypothesized that greater degree of the reticence of PI3K/Akt/mTOR pathway mediated by mTOR inhibitor intensified the sensitivities of the cells of breast cancer to honokiol. Also the combination treatment of honokiol and mTOR inhibitor would be capable of treatment of breast cancer. Thus, inhibition of PI3K/Akt was predicted be one of the mechanisms for its anticancer activity.

\section{MATRINE}

Matrine, is an alkaloid present in Sophora flavescens Ait, a Chinese herb. It exhibits several biological activities like anticancer, antiinflammatory, antiviral, antifibrotic, antiarrhythmic, and immunosuppressive effects (Zhang et al., 2001; Long et al., 2004; Li et al., 2009, 2010; Huang et al., 2014; Yong et al., 2015).

Liu et al. evaluated the effect of novel matrine derivative $[(6 \mathrm{aS}, 10 \mathrm{~S}, 11 \mathrm{aR}, 11 \mathrm{bR}, 11 \mathrm{cS})-10$-methylamino-dodecahydro3a, 7a-diaza-benzo (de) anthracene-8-thione] MASM on human hepatoma cells (HCC) (Hep3B and Huh7) and hepatic cancer stem-like cells (hepatic CSC) Hep3B and Huh7 cell lines. HCC cells were exposed to different concentrations of MASM for 24, 48 , and $72 \mathrm{~h}$ and hepatic CSC for $24 \mathrm{~h}$, cell proliferation for HCC was evaluated by cell counting kit- 8 and programmed cell death by Hoechst 33258 fluorescence staining kit for hepatic SCS respectively. MAMS was found to attenuate phosphorylation of PI3K P110a (a subunit of PI3K) in HCC cells. The PI3K/Akt pathway contributed to, inhibition of MASM on HCC cells and Hepatic CSC. In addition, this study demonstrated that MASM inhibited hepatic CSCs induced cell apoptosis and growth arrest. Further that MASM suppressed hepatoma cell proliferation, and the Akt/mTOR/ p70S6K and Akt/GSK3 $\beta / \beta$-catenin signaling pathways, offering possible mechanisms for its antitumor activity (Liu et al., 2016). 


\section{PARTHENOLIDE}

Parthenolide, is a sesquiterpene lactone isolated from feverfew botanically known as Tanacetum parthenium. It is has been preferred in headache, treatment of arthritis and fever (Knight, 1995). Parthenolide also possesses anticancer activity, therefore used against numerous cancers involving organs like bowel, prostate gland, skin, breast, bile duct, pancreas, and others (Zhang et al., 2004; Kim et al., 2005; Liu et al., 2010; Sun et al., 2010; D’Anneo et al., 2013a,b).

Jeyamohan et al. examined the action of Parthenolide on programmed cell death and autophagy in HeLa cells of cervical cancer. HeLa cells lines were treated with different concentrations of Parthenolide and incubated overnight. 3-(4, 5dimethylthiazol-2-yl)-2, 5-diphenyl terazolium bromide (MTT) assay was carried out to evaluate the cytotoxicity potential of Parthenolide on HeLa cells. The $\mathrm{IC}_{50}$ value was found to be $6 \mu \mathrm{M}$. p-Akt protein expression was found to be downregulated and ATG3 protein expression was found to be upregulated. It was concluded that Parthenolide resulted in PI3K/Akt pathway inhibition which induces autophagy in Hela cells, triggering apoptosis and autophagy via activation of PTEN expression (Jeyamohan et al., 2016).

\section{PLUMBAGIN}

Plumbagin is a naphthoquinone (PLB, 5-hydroxy-2-methyl-1, 4-naphthoquinone) found in Plumbago zeylanica L, Juglans cinerea, Juglans regia, and Juglans nigra. It is used as antiinflammatory, neuroprotective agent and it possesses activities like hypolipidemic, anticancer, antiatherosclerotic, antifungal, and antibacterial (Padhye et al., 2012).

$\mathrm{Li}$ et al. evaluated the apoptotic action of autophagic cell death in A549 and H23 human non-small cell lung cancer cells. PLB promoted autophagy in A549 and H23 cells through reticence of PI3K/Akt/mTOR pathway by inhibiting the Akt activation along with downstream targets, which includes mTOR, glycogen synthase kinase $3 \mathrm{~b}$ and forkhead transcription factors (Kuo et al., 2006). It was concluded that PLB inhibited cell proliferation and enhanced intracellular ROS level, predominantly through the activated mitochondria-dependent apoptotic pathway and induced autophagy to a lesser extent in human A549 and H23 cells via PI3K/Akt/mTOR pathway inhibition (Li et al., 2014).

Zhou et al. evaluated the action of Plumbagin (PLB) on human prostate cancer cell lines viz., PC-3 and DU145. PLB induced apoptosis was observed and autophagy was analyzed using confocal microscopy and flow cytometric analysis. Cell line incubated with PLB showed an increase in autophagy when incubated for $24 \mathrm{~h}$. It was found that PLB stimulated programmed cell death and autophagy through PI3K/Akt/mTOR-mediated pathway (Zhou et al., 2015).

Wang et al. evaluated the action of PLB in human pancreatic cancer cells which involved PI3K/Akt/mTOR-mediated pathway. PANC-1, and BxPC-3 cells, were exposed to PLB to evaluate the cell killing action. Treatment with PLB on BxPC-3 and PANC-1 cells lead to an evidential change in functional proteins' expression along with its phosphorylation level which modifies autophagy signaling pathway.Thus, a concentration-dependent reduction in the level of phosphorylation was witnessed in the case of PI3K, Akt, and mTOR for the cells treated with different concentrations of PLB. Previous studies revealed the induction of autophagy by PLB in different cancer cell lines via the negative PI3K/Akt/mTOR axis modulation (Kuo et al., 2006; Li et al., 2014) As per Wang's previous data autophagy was induced through inhibition of the PI3K/Akt/mTOR pathway in non-small-cell lung cancer cells. Hence, it was concluded that inhibition of PI3K/Akt/mTOR signaling pathway leads to autophagy effect induced by PLB in PANC-1 and BxPC-3 cells (Sun et al., 2015).

Pan et al. analyzed the effect of PLB on programmed cell death, cell cycle distribution and autophagy, in human tongue squamous cell carcinoma cells. Phosphorylation of phosphatidylinositol, phosphatidylinositol-4, phosphatidylinositol-4-phosphate and 5-bisphosphate catalyzed by PI3K catalyze resulted in the formation of phosphatidylinositol-3, 4, 5triphosphate. The phosphorylation effect is stimulated by growth factors and hormones, which modulates cell survival, cell cycle migration, and proliferation. In this study, a dose-dependent phosphorylation was significantly inhibited of PI3K at Tyr458 when compared to control. The phosphorylation level of PI3K at Tyr458 was attenuated depending on the concentration of PBL exposed when compared to the control. Thus, it was concluded that PLB inhibited phosphorylation of PI3K at Tyr199 and p38 MAPK at Thr180/Tyr182 but intensify the phosphorylation of GSK3ßat Ser9 in SCC25 cells, contributing to the increase in autophagy flux (Pan et al., 2015).

Wu et al. (2016), investigated the potential anticancer effect and mechanism of PLB on multiple myeloma (MM) cells. OPM1 cells were incubated with PBL for $24 \mathrm{~h}$ to examine the expression of PI3K and p-Akt using western blot analysis, which disclosed that the anticancer effect of PLB was mediated via the PI3K/Akt signaling pathway in OPM1 cells. Thus, the results of this study concluded, that PLB inhibits cell proliferation and promotes apoptosis of MM cells. Further, the study identified $\mathrm{PI} 3 \mathrm{~K} / \mathrm{Akt} / \mathrm{mTOR}$ pathway to be the potential cellular mechanism of PLB in MM cells.

\section{TRIPTOLIDE}

Triptolide (TPL) is obtained from Thundergod vine, Tripterygium wilfordii Hook, and is used as an anti-inflammatory agent in case of rheumatoid arthritis. It is also established for treatment of variety of cancers (Shu et al., 2009; Zhu et al., 2010; Johnson et al., 2011; Manzo et al., 2012; Zhong et al., 2013; Shao et al., 2014; Li H. et al., 2015; Ziaei and Halaby, 2016). However, previous studies have evaluated the anticancer and sensitization effect of TPL in Epithelial Ovarian Cancer (EOC).

$\mathrm{Hu}$ et al. evaluated effect of triptolide (TPL) in vitro on proliferation, cycle distribution, programmed cell death, and ultrastructure of COC1/DDP cells, also the sensibilization and anticancer effect in vivo. The cell lines were exposed to different concentrations of TPL. TPL was found to display apoptosis induction via the restraint of NF- $\mathrm{B}$ in p53-independent 
pathway, with production of ROS and inactivating the PI3K/Akt signal pathway (Sandler et al., 1997; Lee et al., 2002; Kim et al., 2010; Morgan and Liu, 2011; Zhong et al., 2013; King et al., 2015). The PI3K/Akt pathway tends to upregulate in $30-50 \%$ of prostate cancers, and molecular changes have been demonstrated in the PI3K/Akt to distinguish malignant from benign prostatic epithelium and have been related with growing tumor grade, stage, and risk of recurrence (Luo et al., 2003; Hennessy et al., 2005; Morgan et al., 2009). Thus, it was concluded, that TPL boosted cell apoptosis and suppressed tumor growth via the PI3K/Akt pathway. Further that the sound sensibilization effect of TPL assisted DDP to lower the resistance of epithelial ovarian cancer (EOC) to cisplatin (Hu et al., 2016).

Hyoung et al. analyzed, the effect of BIIB021 alone or in combination with the histone acetyltransferase inhibitor (HAT) TPL on the survival of $8505 \mathrm{C}$ and TPC-1thyroid carcinoma cells (TCC). The drugs when treated as a single agent shows cytotoxic activities by modulating PI3K/Akt and NF- $\mathrm{KB}$ signal pathways (Böll et al., 2009; Xu et al., 2010; Gopalakrishnan et al., 2013; Li et al., 2013; Lin et al., 2014). Thus, they concluded synergistic activity of BIIB021 in combination with TPL participating in suppression of NF- $\mathrm{KB}$ and PI3K/Akt/mTOR signal pathways in TCC (Kim et al., 2016).

Miyata et al. demonstrated effect TPL, on human fibrosarcoma in a dose-dependent manner on HT-1080, human squamous carcinoma, and human uterine cervical carcinoma SKG-II cells. TPL initiated inhibition of PI3K which further lead to an increase in JNK1 activation through Akt and/or protein kinase C (PKC)-independent pathway(s). Ras-Raf-MEK1/2 and PI3K-Akt are intracellular signaling pathways which play a crucial role to regulate tumor cell proliferation (Martin, 2003; Osaki et al., 2004), hence the association of a signal pathway with TPL-induced inhibition was examined, using HT-1080 cells. The results revealed the inhibition of the PI3K action of TPL which corresponds to antiproliferative effect in HT-1080 cells via Akt and/or the PKC-independent pathway(s). Also, it was analyzed that evidential reduction in PI3K inhibition by TPL resulted in an activation of JNK1, which was reponsible for its anti-tumor activity. Thus, the evidence that the reduction in PI3K activity by TPL resulted in the inhibition, which further induced apoptosis (Miyata et al., 2005).

\section{WOGONIN}

Wogonin, 5,7-dihydroxy-8-methoxy-2-phenylchromen-4-one is the major active constituent present in the root of the Scutellaria baicalensis Georgi, a Chinese herb used in various diseases due to its antibacterial, antiviral, antioxidant, anti-inflammatory, and anticancer effects (Li-Weber, 2009; Gasiorowski et al., 2011).

$\mathrm{Hu}$ et al. evaluated apoptosis and endoplasmic reticulum stress in HL-60 leukemia cells. HL-60 cells were evaluated with different concentration of wogonin. The viability of HL-60 was inhibited in a dose-dependent manner. The results revealed inhibition of phosphorylation of PI3K by Wogonin at Tyr458 and Akt at Ser473 in concentration dependent manner. It was hypothesized that PI3K/Akt signaling pathway exhibited a crucial role in programmed cell death in HL-60 from previous studies, induction of apoptosis through the PI3K/Akt pathway in HT29 human colorectal cancer cells (Kim et al., 2012) and in a human myeloma cell line (Zhang et al., 2013). Hence wogonin was proven to possess a potential for human leukemia treatment (Hu et al., 2015).

Huang et al. examined the function of wogonin in the MCF-7 breast cancer cell lines. Western blotting analysis was carried out to study the phosphorylation of PI3K/Akt (p-PI3K/p-Akt). The Western blotting analysis showed decreased in phosphorylation after treatment with wogonin for $24 \mathrm{~h}$ and further quenched after $48 \mathrm{~h}$ treatment. Thus, it was concluded, that wogonin showed programmed cell death in the MCF-7 breast cancer cell lines, which was linked to down-regulation of survivin and Bcl-2; up-regulation of P53, Bax and caspase-3 activation,. Also, pathways of PI3K/Akt and MAPK/ERK showed significant role in programed cell death of MCF-7 induced by wogonin. Inhibition of the PI3K/Akt pathway by wogonin may be due to down-regulating survivin expression, a downstream target of the PI3K/Akt pathway (Huang et al., 2012).

Further Zhao $\mathrm{K}$ et al. observed the activity of wogonin in inhibiting LPS-induced tumor angiogenesis in MCF-7 cells. Western blot investigation was conducted to examine the action of wogonin on PI3K/Akt/NF- $\mathrm{KB}$ signaling pathway on cell lines treated with wogonin. Wogonin efficiently suppressed the expression of PI3K and phosphorylation of Akt activated by LPS in a concentration-dependent manner. But the total protein level of Akt remained unaltered. These results suggested that wogonin could block LPS-triggeredPI3K/Akt signaling. Collectively wogonin inhibit LPSp IGF-1-induced VEGF expression, HUVECs migration, and tube formation via suppression of PI3K/ Akt signaling (Zhao et al., 2014).

\section{THYMOQUINONE}

Thymoquinone (TQ) 2-methyl-5-propan-2-ylcyclohexa-2, 5diene-1, 4-dione is a bioactive constituent of black seed oil (Nigella sativa). It possesses anti-inflammatory effects and also provides protection against a bronchial headache, asthma, and dysentery, gastrointestinal problems (Woo et al., 2012).

Gemcitabine-based chemotherapy is employed in pancreatic cancer (Stathis and Moore, 2010; Mu et al., 2015). Mu et al. employed a combination treatment of TQ and gemcitabine to aim molecular targets to prevent gemcitabine sensitivity and to induce an apoptotic effect on pancreatic cancer cells, as well as reducing the effective dose of gemcitabine (Banerjee et al., 2009; Rajput et al., 2013). TQ displayed itself as a potential chemosensitizer and apoptotic agent via suppression of the PI3K/Akt/mTOR activation along with suppression of downstream effector S6 ribosomal protein which is associated with the chemoresistance of human malignancies to standard anticancer drugs (Yang et al., 2014). TQ showed chemo-sensitizing and apoptotic effects via a decrease in activation of the downstream effector S6 ribosomal protein and PI3K/Akt/mTOR. Thus, it was concluded that the combination forbids gemcitabine sensitivity and induces 
apoptosis in pancreatic cancer cells by avoiding Notch1/PTEN, $\mathrm{PI} 3 \mathrm{~K} / \mathrm{Akt} / \mathrm{mTOR}, \mathrm{NF}-\kappa \mathrm{B}$ pathways. Thus, the observation confirmed that the proposed novel synergistic combination leads to reduction in the dose of Gemcitabine which could reduce the risk of gemcitabine- insensitivity and toxicity. This provides a promising approach in human pancreatic cancer treatment.

Iskender et al. evaluated the effects of TQ and myrtucommulone-A (MC-A), EMT on HTB-9 and MDAMB-231 cell lines. Both MC-A and TQ inhibited epithelialmesenchymal transition by hindering phosphorylation of several components participating in PI3K/Akt axis as well as MAPK/ERK pathways in a dose dependent manner and reversed TGF-b-induced EMT. MC-A and TQ treatment lead to a consistent decrease in the expression of EMT-related markers. It also obstructed the migratory ability of both HTB-9 and MDA-MB-231 cell lines. The study concluded that MC-A or TQ exhibits antimetastatic effects due to inhibition of PI3K/Akt pathway (Iskender et al., 2016).

Dirican et al. evaluated docetaxel and TQ combination for synergistic cytotoxicity effects and also whether this induction was linked to inhibition of MAPK/ERK and PI3K/Akt pathways. The combination treatment showed inhibition of PI3K/Akt pathway where TQ exhibited a crucial role in synergistic cytotoxic and apoptotic effect in hormone and drug-refractory in DU-145 cell lines. The data revealed a possibility of dose reduction of docetaxel with reduced side effects by its novel combination with TQ which could be of greater potential in patients with castrate-resistant prostate cancer (Dirican et al., 2015).

$\mathrm{Xu}$ et al. evaluated the anticancer effect related with PI3K/Akt signaling on TFK-1 and HuCCT-1 cells. In vitro studies in cholangiocarcinoma (CCA) cells revealed that TQ controlled PI3K and Akt activation. TQ showed downregulation of $\mathrm{p}$-Akt in both of the CCA cells while Akt protein level left unaltered. In addition, the downregulation of $\mathrm{p}$-Akt was related to the downregulation of XIAP and Bcl-2, as well as the upregulation of BAX, which evidenced apoptosis induction in cells exposed to TQ for $48 \mathrm{~h}$. The results proposed that PI3K/Akt signaling was partially, involved in this effect. TQ mediated inhibition on NF- $\kappa \mathrm{B}$ was also tested. The results revealed marked decrease in expression of COX-2, VEGF, and cyclin B1, which tends to be regulated via NF- $\mathrm{B}$. These observations were invariable with increased inhibition of growth and apoptosis cell death inducing effects, proposing that TQ inhibits DNA-binding activity of NF$\kappa \mathrm{B}$ in vitro and the downstream gene products expression. This effect was partially accountable for the increased cell killing effect (Xu et al., 2014). The study also revealed that TQ exhibited a chemopreventive effect against human CCA cells by inhibiting the constitutive activation of proinflammatory transcription factors, including both NF- $\mathrm{B}$ and PI3K/Akt. Thus, it was concluded that TQ treatment results in downregulation of antiapoptotic and pro-survival proteins which are transcriptionally regulated by the NF- $\mathrm{B}$ and $\mathrm{PI} 3 \mathrm{~K} / \mathrm{Akt}$ pathways, leading to a loss of CCA cell survival and proliferation. Therefore, TQ is stated as a novel therapeutic regimen for the NF- $\kappa \mathrm{B}$ and $\mathrm{PI} 3 \mathrm{~K} / \mathrm{Akt}$ pathways inactivation in case of human CCA.
$\mathrm{Yu}$ and Kim, examined the effect of TQ on the programmed cell death of chondrocytes on the production of ROS. The chondrocytes were evaluated with increasing concentration of TQ to detect the apoptosis effect. It has been shown that MAPKs and $\mathrm{PI} 3 \mathrm{~K} / \mathrm{Akt}$ signaling pathways could play a role as a mediator in apoptosis (Lee et al., 2000; Aggeli et al., 2006). Also, p38 kinase and PI3K/Akt signaling pathway play an important role in apoptosis induced by TQ. Western blot study detected the expression of PI3K/Akt and MAPKs, p38kinase, ERK-1/-2, and JNKinase, in cells treated with TQ. It resulted in an increase MAPKs and PI3K/Akt, p38kinase, JNKinase and ERK-1/-2 in a dosedependent manner. Together, the results concluded that TQ lead to ROS induced apoptosis via PI3K/Akt and p38kinase pathways in rabbit's articular chondrocytes. Thus, it was concluded that raised ROS levels tends to inhibit proliferation and cause apoptosis in cells that are malignant by activation of both stress kinase and caspase pathways, which includes MAPKs and PI3K/Akt pathways (Onyango et al., 2005; Zanotto-Filho et al., 2010; Kwon et al., 2011; Singh et al., 2011). It was found that ROS induced by TQ enhanced the PI3K/Akt activation and MAPKs, which also leads to apoptosis. Thus, TQ is capable not only to inhibit proliferation but also to induce apoptosis through p38kinase and Akt pathways (Yu and Kim, 2013).

\section{ANDROGRAPHOLIDE}

Andrographolide,(3E,4S)-3-[2-[(1R,4aS,5R,6R,8aS)-6-hydroxy5-(hydroxymethyl)-5,8a-dim-ethyl-2-methylidene-3,4,4a,6,7,8hexahydro-1H-naphthalen-1-yl] ethylidene]-4-hydroxyoxolan2-one is the bioactive constituent present in the Andrographis paniculata extract. It is also utilized for treating upper respiratory tract infections, fever, diarrhea, rheumatoid arthritis, and recently, also shown to possess anti-inflammatory, immune modulatory, anticancer effects (Li et al., 2007)

Kumar et al. studied andrographolide induced programmed cell death and autophagy in U937 cells, human leukemic cells. U937 cells were treated with andrographolide and further densitometric analysis was conducted. As pathway of $\mathrm{PI} 3 \mathrm{~K} / \mathrm{Akt} / \mathrm{mTOR}$ has prototypic functions in cellular proliferation, growth, differentiation, and survival, inhibition of these pathways would be a promising tool against cancer (LoPiccolo et al., 2008). The phosphorylated PI3K expression (pPI3K) was markedly attenuated in AG-4 treated cells in case of both in phosphorylated forms of 85 and 55 PI3K compared to control, in a time-dependent way. Densitometric analysis disclosed the ratios of $\mathrm{pPI} 3 \mathrm{~K}$ (p85)/total PI3K, timedependent drop-off after AG-4 treatment by $78.9-97.8 \%$ as against the control cells. Thus, the downregulation of PI3K/Akt tends to have a crucial role in $A G-4$ induced cytotoxicity. Hence it was concluded that AG-4 regulates pPI3K, pAkt, pmTOR, along with other key molecules pPDK1, pcRaf and pGSK3 $\beta$ of PI3K/Akt/mTOR pathway. Further examination demonstrated that $\mathrm{AG}-4$ elicited cytotoxicity which involved redox imbalance and apoptosis cell death by inducing mitochondrial depolarization and the caspase cascade activation related to inhibition of pathway of PI3K/Akt/mTOR (Kumar et al., 2015). 
Li et al. studied inhibition of HIF1 by andrographolide through PI3K/Akt pathway. PI3K/Akt signaling downregulation by Andrographolide prevents invasion and migration of A549 cells human non-small cell lung cancer (Lee et al., 2010). Previous data suggested a translation of HIF $1 \alpha$ mRNA is under the criterion of a PI3K signaling pathway in several cell types (Laughner et al., 2001; Treins et al., 2002). To analyse the effect of Andrographolide on HIF1 $\alpha$ upstream PI3K/Akt/mTOR pathway, experiments were carried out on MDAMB231 cells, which revealed phosphorylation under hypoxia on mTOR, 4EBP1, and P70S6K. The results revealed attenuation in the Akt, mTOR, and p70s6k phosphorylation level along with suppressed HIF1 $\alpha$ activity by inhibiting the upstream pathway of PI3K/Akt/mTOR. The PI3K/Akt pathway plays a crucial role in the controlling of HIF $1 \alpha$ translation and synthesis in certain types of cancer cells (Jiang and Liu, 2008; Li et al., 2015). These observations supported the possibility that Andrographolide mediates HIF1 $\alpha$ inhibition, which might be dependent on PI3K/Akt pathway by preventing HIF1 $\alpha$ translation (Li et al., 2007).

Lee et al. also studied the inhibitory effects of andrographolide on migration and invasion in cells lines (A549) of human non-small cell lung cancer. A549 cell lines were incubated with andrographolide for $24 \mathrm{~h}$. As per previous data, MAPK and PI3K/Akt is associated with NSCLC cell metastasis and migration (Choudhury et al., 1997; Duan et al., 2000). The incubated cells showed a concentration-dependent decrease of phospho-Akt and PI3K levels and no effect on MAPK including p38MAPK, N-terminal kinase (JNK), c-Jun and an extracellular signal-regulating kinase 2 (ERK2). Depending on the dose or concentration range, andrographolide restrained the PI3K expression and phospho-Akt coexisting with cell invasion and migration mechanism. Thus, it was concluded Andrographolide treatment prevented cell migration/invasion through PI3K/Akt signaling down-regulation and a further cJun/c-Fos (heterodimer complex AP-1) inactivation, that was followed by a depletion of expression MMP-7 (Lee et al., 2010).

$\mathrm{Li}$ et al. further analyzed the inhibitory growth effect and mechanisms of andrographolide on U251 and U87 cell lines, human glioblastoma cells. As per studies deactivation of PI3K/Akt signaling has been said as an important target glioblastomas treatment (Kubota et al., 2000; Gharbi et al., 2007). Andrographolide prevented the invasion and migration in cell lines A549 via PI3K/Akt signaling down-regulation (Lee et al., 2010) which plays an essential role in andrographolideinduced prohibition of proliferation and G2/M arrest. Yanchun Li observed that andrographolide exposure markedly attenuated the phosphorylated levels of $\mathrm{PI} 3 \mathrm{~K}, \mathrm{Akt}, \mathrm{mTOR}$, and $\mathrm{p} 70 \mathrm{~s} 6 \mathrm{k}$ proteins in both U251 and U87 cells. Also, andrographolide effect on signaling of PI3K/Akt prevented G2/M arrest and proliferation in glioblastoma cells, U251 and U87 cells when evaluated in combination with PI3K/Akt inhibitor LY294002. It showed an additive effect on $\mathrm{G} 2 / \mathrm{M}$ arrest and proliferation inhibition. Thus, it was concluded that andrographolide inactivated the prosurvival signaling of PI3K/Akt, which may play a critical role in the $\mathrm{G} 2 / \mathrm{M}$ arrest and prevents proliferation by andrographolide in human glioblastoma cells ( $\mathrm{Li}$ et al., 2012).

\section{RESVERATROL}

Resveratrol (5-[(E)-2-(4-hydroxyphenyl) ethenyl] benzene-1, 3 -diol) is obtained from red wine, peanuts, grapes. It has antiviral, anti-inflammatory, antileukemic, neuroprotective, chemoprotective, and anti-oxidant activities. It is effective as an anticancer agent.

As per Jiang and Liu, PI3K/Akt/mTOR pathway was downregulated by resveratrol. Induction of cell death by inducing caspase- 3 activation carried out by signaling proteins was found to be enhanced by resveratrol (Jiang and Liu, 2008; Jing et al., 2016).

Rachid et al. investigated mechanism of resveratrol mediated regulation of the gene expression of the genes that are a part of PI3K/Akt signaling in cells of human breast cancer (MDA-MB231). They used a microarray that is PI3K-Akt pathway-focused with 96 genes, associated with PI3K-Akt signaling pathways. For signal normalization, they used 10 house keeping genes. As per their results, PDPK1 was the gene in the microarray which was upregulated by more than 15 -fold. This is the kinase that phosphorylates RSK, PKB/Akt. According to their data, after resveratrol treatment, there was an alteration in 13 genes. Also, c-fos and P70S6K were regulated (Rachid and Alkhalaf, 2006).

Kwon et al. studied the apoptosis induction in cells of breast cancer (MDA-MB-231) by resveratrol. Their result of MTT assay showed that there were a time and concentration dependent reduction in viability of the cell. As per their results, there was a time-dependent reduction in the expression of PI3K/Akt by resveratrol. On the other hand, the expression of cleaved-caspase3, p53, and cleaved-caspase-9, was increased. Tumor volume was significantly decreased (Kwon J. K. et al., 2012).

As per Frojdo et al. (2007) resveratrol inhibited the catalytic subunits of PI3K class IA viz. p110 $\alpha$ and $\mathrm{p} 110 \beta$ which further blocks PI3K-PKB pathway. Resveratrol also inhibits the phosphorylation of PI3-kinase (Frojdo et al., 2007). Immunoprecipitation assay and kinase assay by Benitez et al. in LNCaP and PC-3, resveratrol led to inhibition of Era- and AR-dependent PI3K activities. This led to decrease in protein kinase B/Akt phosphorylation and also the phosphorylation of glycogen synthase kinase-3 (GSK-3). The dephosphorylation of GSK-3 further led to decrease in cyclin D1 levels (Benitez et al., 2007).

Wang et al. investigated the resveratrol utility in PC-3 cancer cells. The purpose was to study its effect on apoptosis of prostate cancer and EMT. For this, they used Western blotting using real-time PCR, and fluorescence-activated cell sorting etc. As per their results, resveratrol modulates EMT and apoptosis through PI3K/Akt pathway in prostate cancer (Wang et al., 2016). As per studies carried out by Aziz et al. resveratrol inhibited the activation of PI3K/Akt. This lead to apoptosis of LNCaP cells by modulating Bcl-2 family proteins. Thus, resveratrol was found to be effective in prostate cancer by inhibiting PI3K (Aziz et al., 2006).

\section{EPIGALLOCATECHIN-3-GALLATE}

Epigallocatechin-3-gallate

(3,4,5-trihydroxyphenyl)-3,4-dihydro- 2H-chromen-3-yl] 
3,4,5-trihydroxybenzoate (EGCG) is the main catechin extracted from green tea. It accounts for about $50-80 \%$. It is used in improving cardiovascular health, in cancer chemoprevention, it protects skin from damage caused by ionizing radiation, and it is used as the anti-obesity agent.

The effect of EGCG in pancreatic cells on PI3K/Akt/mTOR pathway was determined by Liu et al. They utilized MTT assay to study the cell proliferation and flow cytometry was utilized to study apoptosis of PANC-1 cells. They utilized western blotting to evaluate the expression of proteins involved while RT-PCR was utilized to determine the expression of the genes which are a part of PI3K/Akt/mTOR pathway. Their observations indicated that the proliferation of PANC-1 cells was inhibited by EGCG and it also induced apoptosis. It upregulated protein and PTEN mRNA expression levels and downregulated the expression of phosphor-mTOR and phosphor-Akt (Liu et al., 2013).

Nomura et al. studied the effect of EGCG PI3K (activated UVB) in epidermal cells JB6 $\mathrm{Cl} 41$ of a mouse. As per their results, the activation of PI3K via UVB was inhibited by pretreatment of these cell with EGCG. Further, activation of PI3K and Erk in UVB signaling was inhibited by EGCG. Also, it attenuated activation of p70 S6-K and Akt which are downstream effectors of PI3K (Nomura et al., 2001).

\section{QUERCETIN}

Quercetin [5,7-dihydroxy-2-(4-hydroxyphenyl)chromen-4-one] is obtained from green tea, red wine, apples, onions, Ginkgo biloba, St. John's wort. Buckwheat tea contains a major amount of quercetin. It is used for treatment of hay fever, diabetes, peptic ulcer, cataracts, asthma, schizophrenia, gout inflammation, viral infections, and cancer.

Xiang et al. explored how quercetin affects the proliferation and apoptosis of HeLa cells. They incubated HeLa cells with quercetin at various concentration levels. They determined the cell viability by MTT assay, cell apoptosis with Annexin-V/PI double labeled cytometry and DNA ladder assay. Cell cycle was flow cytometrically determined. They used a fluorescence microscope after Hoechst 33258 staining to observe the changes in the morphology in the cells. Western blotting was performed to evaluate the proteins related to apoptosis in the HeLa cells. Their results showed that quercetin caused inhibition of HeLa cell growth and induced apoptosis in vitro in a timeand concentration-dependent manner. As per their results, quercetin treatment led to the downregulation of the PI3K and p-Akt expression. In addition, quercetin could down-regulate expression of bcl-2, up-regulate Bax, but exerted no effect on the overall expression of Akt. Thus, they concluded that quercetin induced apoptosis via PI3K/Akt pathways (Xiang et al., 2014).

Study of Maurya et al. used Dalton's lymphoma mice to study the mechanism of quercetin regulating PI3K/Akt pathway. They analyzed the effect of quercetin on the expression and the levels of Akt1, p53, and PI3K in ascite cells. As per their results, in ascite cells of Dalton's lymphoma mice, PI3K signaling was hyperactivated. This led to Akt activation and p53 inactivation. Also, the longevity of mice and morphological parameters confirmed tumor suppressor activity of quercetin. Thus, it was concluded that quercetin may lead to prevention of lymphoma prevention by downregulation PI3K-Akt1-p53 pathway (Maurya and Vinayak, 2016).

\section{FISTEIN}

Fistein [2-(3, 4-dihydroxyphenyl)-3, 7-dihydroxychromen-4one] is obtained from vegetables and fruits such as grape, strawberry, cucumber, and persimmon. It possesses antioxidant, anti-inflammatory, anticancer and scavenging activities (Khan et al., 2013).

Adhami et al. studied effect of fistein against prostate, pancreatic, and lung cancer. For their study, they used prostate and lung adenocarcinoma cell lines. According to their results, fistein inhibited PI3K/Akt pathway and mTOR pathway. Also fistein when used in combination with other anticancer agents, enhanced their cytotoxic effects (Adhami et al., 2012).

Khan et al. found out that in NSCLC cells fistein suppressed the signaling of PI3K/Akt and mTOR and also inhibited cell growth. Fistein inhibited phosphorylation of mTOR, Akt, eIF-4E, p70S6K1, and 4E-BP1. PI3K (p85 and p110) protein expression was also reduced by fistein (Khan et al., 2012).

\section{LUTEOLIN}

Luteolin [2-(3,4-dihydroxyphenyl)-5,7-dihydroxychromen-4one] is distributed in a many of vegetables, fruits such as celery, olive oil, peppers, rosemary, peppermint, oregano, and thyme. Luteolin has anticancer, antitumorigenic, antioxidant, radical scavenging, and anti-inflammatory activities.

Hong et al. (2014) described luteolin mediated inhibition of the growth of the NSCLC tumor in mice and T790M mutant NSCLC cells proliferation. According to their observations, luteolin inhibited the binding between mutant EGF receptors and Hsp90 and thus led to degradation of EGF receptors. $\mathrm{PI} 3 \mathrm{~K} / \mathrm{Akt} / \mathrm{mTOR}$ pathway for cell survival, cell proliferation Ras/Raf/MAPK pathway are the two main downstream signaling pathways of EGF receptors. In this study, luteolin caused degradation of mutant EGF receptors. It mainly affected $\mathrm{PI}$ K/Akt/mTOR pathway causing a reduction in its activity.

As per the Western blot analysis and kinase assay carried out by Kim et al. (2013). luteolin inhibited expressions of PI3K and Raf and it also attenuated the Akt and MEK phosphorylation. They also carried out a pull-down assay. As per the results of this pull-down assay, there was a non-competitive binding of luteolin with ATP which suppressed Raf activity whereas there was competitive binding of luteolin to ATP which resulted in inhibition of PI3K activity. There was inhibition of tumor volume and tumor nodules by luteolin as shown by an in vivo mouse study (Hong et al., 2014).

\section{APIGENIN}

Apigenin [2-(3, 4-dihydroxyphenyl)-5, 7-dihydroxychromen-4one] is mainly found in onions, tea, parsley, and wheat sprouts. It exhibits therapeutic activities such as anti-inflammatory, sedative and it is also used in prevention and treatment of prostate cancer. It suppresses angiogenesis and tumorigenesis 
in melanoma, skin carcinoma, colon carcinoma, and breast carcinoma.

Ruela-de-Sousa et al. studied the action of apigenin on two models of leukemia including erythroid (TF1 cells) and myeloid (HL60 cells). In these two models, they induced cell death and cell-cycle arrest. According to the observations, apigenin activated PTEN and downregulated PI3K and PDK1 which led to inhibition of PKB/PI3K pathway in HL60 cell lines. However, under apigenin treatment, TF1 did not show any change in PI3K/PKB pathway (Ruela-de-Sousa et al., 2010).

Erdogan et al. analyzed the effect of apigenin on apoptosis, cell stemness, survival, and migration properties in CSCs. Since PI3K/Akt signaling regulates $\mathrm{PCa}$ proliferation and survival, and the inhibition of Akt phosphorylation (pAkt) downregulates NF- $\mathrm{B}$ activation; they decided to analyze the effects of apigenin on this signaling pathway. It was demonstrated that $\mathrm{PI} 3 \mathrm{~K}$ and $\mathrm{NF}-\kappa \mathrm{B}$ were predominantly activated and Akt was predominantly phosphorylated in control CSCs. Treating the cells with apigenin markedly inhibited the expression levels of Akt, PI3K, and NF- $\mathrm{B}$ p105/p50 proteins, and inhibited the phosphorylation of pAkt (Erdogan et al., 2016).

Protein kinases play a crucial role in signal transduction pathways that regulate proliferation of cells, their differentiation, and apoptosis. Therefore, agents which could regulate cellular growth by modulating kinases may be developed as an effective anticancer agent. Shukla et al. evaluated the effect of apigenin in cancer cells of the human prostate. As per their results treatment of asynchronized androgen-responsive LNCaP and cell lines of androgen-refractory PC-3 with apigenin $(1-40 \mu \mathrm{M})$ led to the enhanced arrest of the G0G1 phase cells of the cell cycle. Further treatment of cells with apigenin caused a time and dose-dependent decrease in both retinoblastoma $(\mathrm{Rb})$ protein phosphorylation at Ser807/811 and Ser780 total Rb protein. Apigenin led to MAPK pathway activation and decrease in expression of cyclin D1 protein which in turn decreased the phosphorylation and protein expression of PI3K-Akt and p38. In addition, apigenin led to the loss of phosphorylation of RNA polymerase II, thus inhibiting transcription of the proteins (Shukla and Gupta, 2007).

Way et al. examined the effect of apigenin on many cell lines of human breast cancer exhibiting various levels of HER2/neu expression. They found that apigenin had potent growth inhibitory activity on these cell lines. But in cells with basal levels of HER2/neu, apigenin was less effective. They also investigated the role of PI3K and Akt in cell survival pathway. According to the results, apigenin directly inhibited PI3K activity while the activity of Akt kinase was indirectly inhibited. They also observed inhibition of HER2/neu autophosphorylation and transphosphorylation. Further apigenin prevented the PI3K docking to HER2/HER3 heterodimers and thus inhibited the activity of Akt kinase. Thus, they concluded that cellular effects of apigenin resulted from the loss of expression of HER3 and HER2/neu and inactivation of PI3K and Akt (Way et al., 2004).

\section{INDOLE-3-CARBINOL}

Indole-3-carbinol [1 $\mathrm{H}$-indol-3-ylmethanol] (I3C) is found in cruciferous vegetables such as Brussels cabbage, sprouts, broccoli, cauliflower (Pfeifer and Fahrendorf, 2015). It is mainly used in breast, colon, thyroid, gastric, prostate cancer, and mesothelioma (Fares, 2014).

Mao et al. investigated inhibition of NPC cells by I3C. Various concentrations of I3C were applied on NPC cell lines. The cell proliferation was analyzed at certain time intervals $(0,24,48$, and $72 \mathrm{~h})$. After $48 \mathrm{~h}$, the PI3K/Akt associated proteins levels were determined. Tumors were induced in nude mice and the PI3K/Akt pathway associated proteins levels were determined. According to their results, as the concentration of I3C increased, in PI3K/Akt pathway associated proteins levels and cell proliferation was decreased while there was an increase in apoptosis. Also in the prevention and treatment groups of mice, there was the development of small tumors and also the levels of PI3K/Akt pathway proteins were reduced (Mao et al., 2014).

\section{DI-INDOLYLMETHANE}

Di-indolylmethane [3-(1H-indol-3-ylmethyl)-1H-indole] (DIM) is obtained from condensation reaction of I3C. I3C is used in cancer treatment, it has the disadvantage of being highly unstable. I3C molecules combine in the acidic $\mathrm{pH}$ of the stomach and lead to the formation of a complex mixture of therapeutically active compounds. From this mixture of compounds the most prominent acid condensation product of I3C is the dimer DIM. The yield of DIM is only $10-20 \%$ of the products formed. Formation of DIM from I3C is the pre-requirement for the anti-cancer activity of $\mathrm{I} 3 \mathrm{C}$ as it the most potent condensation product (Ahmad et al., 2013).It is used to prevent uterine cancer, cancer, and colorectal cancer. It is utilized in the treatment of premenstrual syndrome and it prevents an enlarged prostate (benign prostatic hypertrophy, BPH).

Qian et al. assessed the effect of DIM given intranasally against lung tumorigenesis. Lung tumorigenesis was induced in mice using 4-(methylnitrosamino)-1-(3-pyridyl)-1-butanone (NNK). According to their observations, after administration of DIM, there was $72 \%$ reduction in lung tumor multiplicity. In the case of large tumors, there was complete abolishment and for $0.5-1 \mathrm{~mm}$ tumors there was $74 \%$ reduction. There was $82 \%$ reduction in tumor volume. Further they used in vitro lung tumorigenesis model for further studies which showed that in both premalignant and malignant bronchial cells, DIM showed apoptotic and antiproliferative effects and in parental immortalized cells there were minimal effects. These effects were found to be, at least in part through PI3K pathway suppression (Qian et al., 2013).

\section{SULFORAPHANE}

Sulforaphane [(E)-4-isothiocyanato-1-methylsulfinylbut-1-ene] (SFN) is found in cruciferous vegetables and is a major constituent of radish seeds. It shows antimutagenicity, anticancer, and antiviral activities (Yang et al., 2016). 
Effect of SFN on four breast cancer cell lines showed abnormalities in ErbB2/ER-PI3K-Akt-mTOR-S6K1 signaling pathway as reported by Pawlik et al. The breast cancer cell lines used include, MDA MB 468, MDA MB 231, SKBR3, and MCF7. They determined Akt phosphorylation status, cell viability, protein synthesis, cell ultrastructure, autophagy induction, and S6K1 kinases status following SFN treatment. According to their results, all four cell lines showed similar sensitivity to SFN mediated via inhibition of PI3K (Pawlik et al., 2013).

Influence of SFN on ovarian cell lines growth viz; SKOV-3, OVCAR-3, and MDAH 2774 were carried out by Chuang et al. The pathway that was influenced was determined by Chaudhuri et al. while the signaling mechanism by which SFN influences the ovarian cancer cell proliferation and growth was determined by Bryant et al. According to Chuang et al. there was a concentration dependent decrease in cell density. They also carried out analysis of the cell cycle phase progression which showed that in G2M and $S$ phases there was a decrease in cell population while there was an increase in G1 phase cell population which showed arrest of G1 cell cycle. The decrease was found to be dependent on time and concentration. These results indicated the role of SFN in causing apoptosis and growth arrest in cell lines of ovarian carcinoma. Chaudhuri et al. studied the effect of SFN on Akt signal transduction pathway. According to their results, in cell lines of ovarian cancer exposed to sulforaphane, there was a reduction in PI3K, active phosphorylated levels of Akt and total Akt protein. Bryant et al. used gene expression profile analysis and found out that SFN causes the arrest of G1 cell cycle (Chuang et al., 2013).

\section{PHENETHYL ISOTHIOCYANATE}

Phenethyl isothiocyanate [2-isothiocyanatoethylbenzene] (PEITC) is mainly found in crucifers such as cauliflowers and olives. It is mainly used in the treatment of various types of carcinomas.

$\mathrm{Li}$ et al. analyzed the effect of phenethyl isothiocyanate (PEITC) on metastasis and invasion of colon cancer. They cultured SW480 cells for $24 \mathrm{~h}$ with PEITC. MTT assay was utilized to determine cell proliferation. For determination of cell invasion, wound healing assay was used while for determination of cell migration transwell invasion assay was performed. The expression of MMP-9 mRNA was determined using qRT-PCR. The Western blotting study was done to analyze the PI3K and PTEN expression, mTOR and Akt phosphorylation and nuclear translocation of nuclear factor-kappa B (NF-кB). PEITC inhibited invasion and migration of SW480 cell within toxicityfree dose ranges. According to western blotting and molecular data, the expression of PI3K and phosphorylation of mTOR and Akt was inhibited by PEICT (Li et al., 2016).

\section{BENZYL ISOTHIOCYANATE}

Benzyl Isothiocyanate [isothiocyanatomethylbenzene] (BITC) is obtained from cruciferous vegetables such as garden cress. It is mainly used in cancer treatment.
Boreddy et al. hypothesized that the pathway PI3K/Akt/FOXO may be associated BITC induced apoptosis. According to their results, BITC caused tumor growth suppression and enhanced tumor cell apoptosis. This was related to inhibition of PI3K, Akt and FOXO activation. Using Western blot analysis, immunofluorescence, kinase activity, and EMSA it was confirmed that the activated levels of FOXO, PI3K, and Akt were inhibited in pancreatic cells including PanC-1 and BxPC-3. BITC reduced phosphorylation rather than protein levels of $\mathrm{PI} 3 \mathrm{~K}$ in BITC-treated tumors and both PanC-1 and BxPC-3 cell lines. Thus, it was concluded that BITC targeted activated-PI3K and not protein levels to inhibit the growth of pancreatic cancer cells (Boreddy et al., 2011).

\section{DEHYDROGLYASPERIN D}

Dehydroglyasperin D (DHGA-D) is mainly found in liquorice. It has activities such as antiobesity, aldose reductase inhibitory activities, anticancer, and antioxidant activities.

The action of DHGA-D on proliferation of colorectal cancer cells was evaluated by Jung et al. They also determined that primarily DHGA-D targets signaling. In HT-29 human colorectal adenocarcinoma cells, they studied anchorage-independent and anchorage-independent cell growth. They used Western blot analysis along with a particular antibody to determine the target protein of DHGA-D. Kinase and pull-down assays were used to determine the direct interaction between the target protein and DHGA-D. Further to determine the signaling pathway, they used techniques such as flow cytometry and western blot analysis. Pulldown assays and kinase assays showed that PI3K activity was directly suppressed by DHGA-D. According to their study PI3K inhibition downregulated cyclin D1 expression and GSK $3 \beta$ and phosphorylation thus lead to G1 cell arrest in melanoma (Jung and Jeong, 2016).

\section{EVODIAMINE}

Evodiamine is a quinolone alkaloid obtained from a traditional Chinese medicinal plant, Wuzhuyu (Fructus Evodiae Rutaecarpae). Evodiamine exhibits pharmacological activities such as antinociceptive, anti-anoxia, and vasorelaxant properties (Lijuan et al., 2016).

The effects of evodiamine and its mechanism with respect to ovarian cancer cells were explored by Lijuan et al. They treated human ovarian cancer cells (HO-8910PM) with evodiamine and used MTT assay to study the growth inhibition. Propidium iodide (Annexin V-FITC/PI) double staining/Annexin Vfluorescein isothiocyanate assay was used to assess apoptosis induction. Western blot analysis was used to determine the mechanism of apoptosis. Also, the expression levels of proteins of $\mathrm{PI} 3 \mathrm{~K} /$ protein kinase B (Akt) pathway and/or MAPK were determined. According to their results, evodiamine inhibited the HO-8910PM cells proliferation in a concentration and time-dependent manner. Evodiamine decreased activity and expression of Akt, PI3K, p38 MAPK and extracellular ERK1/2 MAPK (Lijuan et al., 2016). 
Evodiamine effect on $\mathrm{K} 1$ cell line of papillary thyroid cancer and its mechanism of action were investigated by Lv et al. MTT assay was used to analyze the action of evodiamine on the proliferation of $\mathrm{K} 1$ cells. Western blot analysis was used in order to evaluate the expressions of proteins related to apoptosis. According to their results, evodiamine inhibited $\mathrm{K} 1$ cells proliferation in a concentration-dependent manner. Furthermore, evodiamine treatment markedly increased ROS generation and $\mathrm{LDH}$ leakage. Also, evodiamine downregulated the expression of p-Akt and PI3K which confirmed association of PI3K/Akt signaling pathway with apoptosis induced by evodiamine (Lv et al., 2016).

\section{PICEATANNOL}

Piceatannol \{4-[(E)-2-(3, 5-dihydroxyphenyl) ethenyl] benzene1, 2-diol\} is resveratrol's natural analog present in red wine, peanuts, grapes (Ko et al., 2012).

It exhibits anticancer and anti-inflammatory properties. It is also used in atherosclerosis, hypercholesterolemia, and angiogenesis (Kershaw and Kim, 2017).

Ko et al. used MDA-MB-231 cells to study the mechanisms anti-invasion shown by piceatannol. According to their result, piceatannol caused a reduction in serum-induced cell invasion, adhesion, and migration but viability of cells was not affected. Further, it inhibited protein levels and mRNA expression, matrix metalloproteinase-9 (MMP-9) activity. It increased tensin homolog (PTEN) and phosphatase and reduced phosphorylation of Akt and phosphoinisitide-3-kinase (PI3K). It also inhibited DNA binding of NF- $\kappa \mathrm{B}$ on MMP-9 promoter and nuclear factor kappa B (NF-кB) transcriptional activity (Ko et al., 2012).

The role of piceatannol in adipogenesis and its mechanism was determined by Kwon et al. According to their observations piceatannol supressed 3T3-L1 preadipocytes adipogenesis at non-cytotoxic concentrations. It also revealed that activity of PI3K and IR kinase is inhibited by piceatannol (Kwon J. Y. et al., 2012).

According to Song et al. piceatannol inhibited invasive phenotype of MCF10A human breast epithelial cells harboring mutated $\mathrm{H}$-ras (H-ras MCF10A cells) and MMP-2 induced by $\mathrm{H}$ ras more efficiently as compared to resveratrol. According to their results, piceatannol reduced the $\mathrm{H}$-ras-induced phosphorylation of Akt in a time- and concentration-dependent manner. In vitro kinase assays revealed that, the activity of PI3K and expression of phosphatidylinositol $(3,4,5)$-trisphosphate (PIP3) in the H-ras MCF10A cells was suppressed by piceatannol. Ex vivo pull-down assays showed that there was direct binding of piceatannol to PI3K and thus inhibited its activity (Song et al., 2013).

\section{ELLAGIC ACID}

Ellagic acid $\quad\{2,3,7,8$-Tetrahydroxy-chromeno[5,4,3cde]chromene-5,10-dione $\}$ is found in strawberries, blackberries, walnuts, and raspberries. It is used to treat bacterial and viral infections and to prevent cancer.

Kowshika et al. used hamster model to examine the expression of protein and transcription of VEGF, hypoxia-inducible factor-1alpha (HIF-1a), members of MAPK, and PI3K/Akt signaling pathway. To determine the mechanism by which ellagic acid works they carried out cell culture experiments and molecular docking studies using endothelial cell line ECV304. They found out that ellagic acid downregulates PDK-1, PI3K, mTOR, p-JNK, p-Aktser473, and p-ERK and thus inhibit HIF-1a-induced VEGF/VEGFR2. It also inhibited hypoxiainduced angiogenesis and neovascularization that reduced the expression of histone deacetylase. Ellagic acid suppressed HDAC6 in ECV304 cells. Molecular docking studies showed that an interaction between ellagic acid and upstream kinase was responsible for regulation of angiogenic signaling (Kowshik et al., 2014).

\section{TIEBTAN MEDICINE}

Tang-Kang-Fu-San (TFKS), a traditional herbal formulation prepared by following the principles of textbook of Tibetan medicine. It is formulated with 11 herbs and is being widely used in different parts of China for the treatment of type 2 diabetes. Formulation also has lot of scientific evidence and clinically proven. To further understand the chemical composition and mechanism, Bailu et al. carried out HPLC fingerprint analysis and in vivo mechanistic studies. Fingerprint analysis could mark 13 peaks and identified one of the chief constituent as gallic acid. Under in vivo mechastic studies, herb was observed for impaired insulin tolerance in $\mathrm{db} / \mathrm{db}$ mice and study identified improved glucose tolerance in mice treated with this Tibetan medicine. To further understand the molecular mechanism, western blotting assay was carried out to measure the level of protein expression of PI3K/Akt and AMPK pathways. And found that NLRC3 mRNA levels were significantly increased compared to metformin which can supresses the downstream of PI3K/Akt pathway to modulate the mTOR activity. The present study outlines that TFKS might be associated with genes regulating PPAR $\gamma$ and NLRC3 or by effecting the potential signal factors of PI3K/Akt or AMPK pathways (Bailu et al., 2017).

\section{CONCLUSION}

Phytochemicals are the paramount cost-effective treatment option for the cancer patients. They are believed to play a crucial role in inhibiting, controlling or blocking the signals that lead to the conversion of normal cells to cancerous cells. Phytochemicals are widely investigated for their potential in cancer treatment and some of them are effective in preventing and treating cancer.

PI3K pathway has a major role in the regulation of growth, proliferation, and survival of cells. Hyperactivation of the PI3K is observed in many types of cancers. It is also implicated in resistance to anticancer treatments such as tyrosine kinase inhibitors, biologics, and radiation. In therapeutic sensitivity restoration, inhibitors of the $\mathrm{PI} 3 \mathrm{~K}$ are tested in combination with the other anticancer treatments in preclinical and clinical studies. The literature has reported various phytochemicals that have shown effective anticancer activity by targeting PI3K. Table 2 provides a detailed overview of clinical trials reported in literature. 
This book chapter provides complete account of the phytochemicals that show anticancer potential by inhibiting PI3K pathway. Many preclinical, clinical, in-vitro studies are being carried out worldwide to determine the efficacy of phytochemicals that inhibit PI3K pathway for cancer treatment. For some of the phytochemicals, in addition to studies on cell lines, clinical trials conducted have shown successful outcomes such as in the case of ellagic acid and indole-3-carbinol. For some of the other phytochemicals such as resveratrol, epigallocatein-3gallate, apigenin, and quercetin, studies on cell lines have given promising results and the clinical trials for these phytochemicals

\section{REFERENCES}

Adhami, V. M., Syed, D. N., Khan, N., and Mukhtar, H. (2012). Dietary flavonoid fisetin: a novel dual inhibitor of PI3K/Akt and mTOR for prostate cancer management. Biochem. Pharmacol. 84, 1277-1281. doi: 10.1016/j.bcp.2012.07.012

Aggeli, I. K. S., Gaitanaki, C., and Beis, I. (2006). Involvement of JNKs and $\mathrm{p} 38$-MAPK/MSK1 pathways in $\mathrm{H} 2 \mathrm{O}$ 2-induced upregulation of heme oxygenase-1 mRNA in H9c2 cells. Cell. Signal. 18, 1801-1812. doi: 10.1016/j.cellsig.2006.02.001

Ahmad, A., Biersack, B., Li, Y., Kong, D., Bao, B., Schobert, R., et al. (2013). Targeted regulation of PI3K/Akt/mTOR/NF- $\mathrm{KB}$ signaling by indole compounds and their derivatives: mechanistic details and biological implications for cancer therapy. Anti Cancer Agents Med. Chem. 13, 1002-1013. doi: 10.2174/ 18715206113139990078

Akinleye, A., Chen, Y., Mukhi, N., Song, Y., and Liu, D. (2013). Ibrutinib and novel BTK inhibitors in clinical development. J. Hematol. Oncol. 6:59. doi: 10.1186/1756-8722-6-59

Al-Amri, A. M., and Bamosa, A. O. (2009). Phase I safety and clinical activity study of thymoquinone in patients with advanced refractory malignant disease. Shiraz E Med. J. 10, 107-111.

Altomare, D. A., and Testa, J. R. (2005). Perturbations of the Akt signalling pathway in human cancer. Oncogene 24:7455. doi: 10.1038/sj.onc.1209085

Aziz, M. H., Nihal, M., Fu, V. X., Jarrard, D. F., and Ahmad, N. (2006). Resveratrol-caused apoptosis of human prostate carcinoma LNCaP cells is mediated via modulation of phosphatidylinositol $3^{\prime}$-kinase/Akt pathway and Bcl-2 family proteins. Mol. Cancer Ther. 5, 1335-1341. doi: 10.1158/1535-7163.MCT-05-0526

Bailu, D., Zhongqiu, Z., Weifang, L., Hui, X., Sisi, L., Liang, Y., et al. (2017). Antidiabetic effect of tibetan medicine Tang-Kang-Fu-san in db/db Mice via activation of PI3K/Akt and AMPK pathways. Front. Pharmacol. 8:535. doi: 10.3389/fphar.2017.00535

Banerjee, S., Kaseb, A. O., Wang, Z., Kong, D., Mohammad, M., Padhye, S., et al. (2009). Antitumor activity of gemcitabine and oxaliplatin is augmented by thymoquinone in pancreatic cancer. Cancer Res. 69, 5575-5583. doi: 10.1158/0008-5472.CAN-08-4235

Bartholomeusz, C., and Gonzalez-Angulo, A. M. (2012). Targeting the PI3K signaling pathway in cancer therapy. Expert Opin. Ther. Targets 16, 121-130. doi: $10.1517 / 14728222.2011 .644788$

Battle, T. E., Arbiser, J., and Frank, D. A. (2005). The natural product honokiol induces caspase-dependent apoptosis in B-cell chronic lymphocytic leukemia (B-CLL) cells. Blood 106, 690-697. doi: 10.1182/blood-2004-11-4273

Benitez, D. A., Pozo-Guisado, E., Clementi, M., Castellón, E., and FernandezSalguero, P. M. (2007). Non-genomic action of resveratrol on androgen and oestrogen receptors in prostate cancer: modulation of the phosphoinositide 3-kinase pathway. Br. J. Cancer 96:1595. doi: 10.1038/sj.bjc.6603755

Böll, B., Eltaib, F., Reiners, K. S., von Tresckow, B., Tawadros, S., Simhadri, V. R., et al. (2009). Heat shock protein 90 inhibitor BIIB021 (CNF2024) depletes NF-кB and sensitizes Hodgkin's lymphoma cells for natural killer cell-mediated cytotoxicity. Clin. Cancer Res. 15, 5108-5116. doi: 10.1158/1078-0432.CCR-09-0213 are ongoing. But still, there are many phytochemicals which have the potential to successfully treat cancer by targeting PI3K such as luteolin, fistein, evodiamine, benzyl isothiocyanate. Research on such phytochemicals is need of the hour.

\section{AUTHOR CONTRIBUTIONS}

VS: contributed toward conceptualization, planning and writing the paper. MM, TK, and PC: contributed toward data collection and writing the paper. PS: contributed toward editing of manuscript.

Boreddy, S. R., Pramanik, K. C., and Srivastava, S. K. (2011). Pancreatic tumor suppression by benzyl isothiocyanate is associated with inhibition of PI3K/Akt/FOXO pathway. Clin. Cancer Res. 17, 1784-1795. doi: 10.1158/1078-0432.CCR-10-1891

Burris, H. A. (2013). Overcoming acquired resistance to anticancer therapy: focus on the PI3K/Akt/mTOR pathway. Cancer Chemother. Pharmacol. 71, 829-842. doi: 10.1007/s00280-012-2043-3

Calleja, V., Laguerre, M., Parker, P. J., and Larijani, B. (2009). Role of a novel $\mathrm{PH}$-kinase domain interface in $\mathrm{PKB} / \mathrm{Akt}$ regulation: structural mechanism for allosteric inhibition. PLoS Biol. 7:e1000017. doi: 10.1371/journal.pbio.1000017

Cantley, L. C. (2002). The phosphoinositide 3-kinase pathway. Science 296, 1655-1657. doi: 10.1126/science.296.5573.1655

Chandra-Kuntal, K., and Singh, S. V. (2010). Diallyl trisulfide inhibits activation of signal transducer and activator of transcription 3 in prostate cancer cells in culture and in vivo. Cancer Prev. Res. 3, 1473-1483. doi: 10.1158/1940-6207.CAPR-10-0123

Cheng, L., Xia, T. S., Wang, Y. F., Zhou, W., Liang, X. Q., Xue, J. Q., et al. (2014). The apoptotic effect of $\mathrm{D}$ Rhamnose $\beta$-Hederin, a novel oleanane-type triterpenoid saponin on breast cancer cells. PLoS ONE 9:e90848. doi: 10.1371/journal.pone.0090848

Choudhury, G. G., Karamitsos, C., Hernandez, J., Gentilini, A., Bardgette, J., and Abboud, H. E. (1997). PI-3-kinase and MAPK regulate mesangial cell proliferation and migration in response to PDGF. Am. J. Physiol. Renal Physiol. 273, F931-F938.

Chuang, L., Nagarsheth, N., Hayes, M. P., Zakashansky, K., GGretz, III, H., Nezhat, F. R., et al. (2013). Sulforaphane induces cell cycle arrest, migration, invasion, and apoptosis in epithelial ovarian cancer cells. Am. J. Cancer Rev. 1, 9-24.

Chun-Guang, W., Jun-Qing, Y., Bei-Zhong, L., Dan-Ting, J., Chong, W., Liang, Z., et al. (2010). Anti-tumor activity of emodin against human chronic myelocytic leukemia K562 cell lines in vitro and in vivo. Eur. J. Pharmacol. 627, 33-41. doi: 10.1016/j.ejphar.2009.10.035

Clark, A. S., West, K., Streicher, S., and Dennis, P. A. (2002). Constitutive and inducible Akt activity promotes resistance to chemotherapy, trastuzumab, or tamoxifen in breast cancer cells. Mol. Cancer Ther. 1, pp.707-717.

Clarke, P. A., and Workman, P. (2012). Phosphatidylinositide-3-kinase inhibitors: addressing questions of isoform selectivity and pharmacodynamic/predictive biomarkers in early clinical trials. J. Clin. Oncol. 30, 331-333. doi: 10.1200/JCO.2011.38.7167

Courtney, K. D., Corcoran, R. B., and Engelman, J. A. (2010). The PI3K pathway as drug target in human cancer. J. Clin. Oncol. 28, 1075-1083. doi: 10.1200/JCO.2009.25.3641

Cui, Y., Lu, P., Song, G., Liu, Q., Zhu, D., and Liu, X. (2016). Involvement of $\mathrm{PI} 3 \mathrm{~K} / \mathrm{Akt}$, ERK and $\mathrm{p} 38$ signaling pathways in emodin-mediated extrinsic and intrinsic human hepatoblastoma cell apoptosis. Food Chem. Toxicol. 92, 26-37. doi: 10.1016/j.fct.2016.03.013

Curry, E. A., Murry, D. J., Yoder, C., Fife, K., Armstrong, V., Nakshatri, H., et al. (2004). Phase I dose escalation trial of feverfew with standardized doses of parthenolide in patients with cancer. Invest. New Drugs 22, 299-305. doi: 10.1023/B:DRUG.0000026256.38560.be

D’Anneo, A., Carlisi, D., Lauricella, M., Emanuele, S., Di Fiore, R., Vento, R., et al. (2013a). Parthenolide induces caspase-independent and AIF-mediated 
cell death in human osteosarcoma and melanoma cells. J. Cell. Physiol. 228, 952-967. doi: 10.1002/jcp.24131

D’Anneo, A., Carlisi, D., Lauricella, M., Puleio, R., Martinez, R., Di Bella, S., et al. (2013b). Parthenolide generates reactive oxygen species and autophagy in MDA-MB231 cells. A soluble parthenolide analogue inhibits tumour growth and metastasis in a xenograft model of breast cancer. Cell Death Disease 4:e891. doi: 10.1038/cddis.2013.415

Ding, Q., Yang, L. X., Yang, H. W., Jiang, C., Wang, Y. F., and Wang, S. (2009). Cytotoxic and antibacterial triterpenoids derivatives from Clematis ganpiniana. J. Ethnopharmacol. 126, 382-385. doi: 10.1016/j.jep.2009.09.028

Dirican, A., Atmaca, H., Bozkurt, E., Erten, C., Karaca, B., and Uslu, R. (2015). Novel combination of docetaxel and thymoquinone induces synergistic cytotoxicity and apoptosis in DU-145 human prostate cancer cells by modulating PI3K-Akt pathway. Clin. Transl. Oncol. 17, 145-151. doi: 10.1007/s12094-014-1206-6

Duan, C., Bauchat, J. R., and Hsieh, T. (2000). Phosphatidylinositol 3-kinase is required for insulin-like growth factor-I-induced vascular smooth muscle cell proliferation and migration. Circ. Res. 86, 15-23. doi: 10.1161/01.RES.86.1.15

Dugasani, S., Pichika, M. R., Nadarajah, V. D., Balijepalli, M. K., Tandra, S., and Korlakunta, J. N. (2010). Comparative antioxidant and antiinflammatory effects of [6]-gingerol,[8]-gingerol,[10]-gingerol and [6]-shogaol. J. Ethnopharmacol. 127, 515-520. doi: 10.1016/j.jep.2009.10.004

Eder, J. P., Woude, G. F. V., Boerner, S. A., and LoRusso, P. M. (2009). Novel therapeutic inhibitors of the c-Met signaling pathway in cancer. Clin. Cancer Res. 15, 2207-2214. doi: 10.1158/1078-0432.CCR-08-1306

Erdogan, S., Doganlar, O., Doganlar, Z. B., Serttas, R., Turkekul, K., Dibirdik, I., et al. (2016). The flavonoid apigenin reduces prostate cancer CD44+ stem cell survival and migration through PI3K/Akt/NF-kB signaling. Life Sci. 162, 77-86. doi: $10.1016 /$ j.lfs.2016.08.019

Fares, F. (2014). The anti-carcinogenic effect of indole-3-carbinol and 3, 3'-diindolylmethane and their mechanism of action. Med Chem. S1:002. doi: 10.4172/2161-0444.S1-002

Fleischauer, A. T., Poole, C., and Arab, L. (2000). Garlic consumption and cancer prevention: meta-analyses of colorectal and stomach cancers. Am. J. Clin. Nutr. $72,1047-1052$.

Frojdo, S., Cozzone, D., Vidal, H., and Pirola, L. (2007). Resveratrol is a class IA phosphoinositide 3-kinase inhibitor. Biochem. J. 406, 511-518. doi: 10.1042/BJ20070236

Gasiorowski, K., Lamer-Zarawska, E., Leszek, J., Parvathaneni, K., Yendluri, B. B., Blach-Olszewska, Z., et al. (2011). Flavones from root of Scutellaria baicalensis Georgi: drugs of the future in neurodegeneration? CNS Neurol. Disord. Drug Targets 10, 184-191. doi: 10.2174/187152711794480384

Gharbi, S. I., Zvelebil, M. J., Shuttleworth, S. J., Hancox, T., Saghir, N., Timms, J. F., et al. (2007). Exploring the specificity of the PI3K family inhibitor LY294002. Biochem. J. 404, 15-21. doi: 10.1042/BJ20061489

Gopalakrishnan, R., Matta, H., and Chaudhary, P. M. (2013). A purine scaffold HSP90 inhibitor BIIB021 has selective activity against KSHVassociated primary effusion lymphoma and blocks vFLIP K13-induced NF-кB. Clin. Cancer Res. 19, 5016-5026. doi: 10.1158/1078-0432.CCR$12-3510$

Hennessy, B. T., Smith, D. L., Ram, P. T., Lu, Y., and Mills, G. B. (2005). Exploiting the PI3K/Akt pathway for cancer drug discovery. Nat. Rev. Drug Discov. 4:988. doi: $10.1038 / \mathrm{nrd} 1902$

Ho, S. C., Chang, K. S., and Lin, C. C. (2013). Anti-neuroinflammatory capacity of fresh ginger is attributed mainly to 10-gingerol. Food Chem. 141, 3183-3191. doi: 10.1016/j.foodchem.2013.06.010

Hong, Z., Cao, X., Li, N., Zhang, Y., Lan, L., Zhou, Y., et al. (2014). Luteolin is effective in the non-small cell lung cancer model with L858R/T790M EGF receptor mutation and erlotinib resistance. Br. J. Pharmacol. 171, 2842-2853. doi: $10.1111 /$ bph. 12610

Hsing, A. W., Chokkalingam, A. P., Gao, Y. T., Madigan, M. P., Deng, J., Gridley, G., et al. (2002). Allium vegetables and risk of prostate cancer: a populationbased study. J. Natl. Cancer Inst. 94, 1648-1651. doi: 10.1093/jnci/94. 21.1648

Hu, C., Huang, L., Gest, C., Xi, X., Janin, A., Soria, C., et al. (2012). Opposite regulation by PI3K/Akt and MAPK/ERK pathways of tissue factor expression, cell-associated procoagulant activity and invasiveness in MDA-MB-231 cells. J. Hematol. Oncol. 5:16. doi: 10.1186/1756-8722-5-16
Hu, C., Xu, M., Qin, R., Chen, W., and Xu, X. (2015). Wogonin induces apoptosis and endoplasmic reticulum stress in HL-60 leukemia cells through inhibition of the PI3K-Akt signalling pathway. Oncol. Rep. 33, 3146-3154. doi: 10.3892/or.2015.3896

Hu, H., Luo, L., Liu, F., Zou, D., Zhu, S., Tan, B., et al. (2016). Anti-cancer and sensibilisation effect of triptolide on human epithelial ovarian cancer. J. Cancer 7:2093. doi: $10.7150 /$ jca. 16178

Huang, K. F., Zhang, G. D., Huang, Y. Q., and Diao, Y. (2012). Wogonin induces apoptosis and down-regulates survivin in human breast cancer MCF-7 cells by modulating PI3K-AKT pathway. Int. Immunopharmacol. 12, 334-341. doi: 10.1016/j.intimp.2011.12.004

Huang, W. C., Chan, C. C., Wu, S. J., Chen, L. C., Shen, J. J., Kuo, M. L., et al. (2014). Matrine attenuates allergic airway inflammation and eosinophil infiltration by suppressing eotaxin and Th2 cytokine production in asthmatic mice. J. Ethnopharmacol. 151, 470-477. doi: 10.1016/j.jep.2013.10.065

Huynh, H. (2010). Molecularly targeted therapy in hepatocellular carcinoma. Biochem. Pharmacol. 80, 550-560. doi: 10.1016/j.bcp.2010.03.034

Iishi, H., Tatsuta, M., Baba, M., Uehara, H., Nakaizumi, A., Shinkai, K., et al. (1997). Inhibition by ginsenoside $\mathrm{Rg} 3$ of bombesin-enhanced peritoneal metastasis of intestinal adenocarcinomas induced by azoxymethane in Wistar rats. Clin. Exp. Metast. 15, 603-611. doi: 10.1023/A:1018491314066

Ishitsuka, K., Hideshima, T., Hamasaki, M., Raje, N., Kumar, S., Hideshima, H., et al. (2005). Honokiol overcomes conventional drug resistance in human multiple myeloma by induction of caspase-dependent and-independent apoptosis. Blood 106, 1794-1800. doi: 10.1182/blood-2005-01-0346

Iskender, B., Izgi, K., and Canatan, H. (2016). Novel anti-cancer agent myrtucommulone-A and thymoquinone abrogate epithelial-mesenchymal transition in cancer cells mainly through the inhibition of PI3K/Akt signalling axis. Mol. Cell. Biochem. 416, 71-84. doi: 10.1007/s11010-016-2697-y

Jeyamohan, S., Moorthy, R. K., Kannan, M. K., and Arockiam, A. J. V. (2016). Parthenolide induces apoptosis and autophagy through the suppression of PI3K/Akt signaling pathway in cervical cancer. Biotechnol. Lett. 38, 1251-1260. doi: 10.1007/s10529-016-2102-7

Jiang, B. H., and Liu, L. Z. (2008). Akt signaling in regulating angiogenesis. Curr. Cancer Drug Targets 8, 19-26. doi: 10.2174/156800908783497122

Jiao, D., Wang, J., Lu, W., Tang, X., Chen, J., Mou, H., et al. (2016). Curcumin inhibited HGF-induced EMT and angiogenesis through regulating c-Met dependent PI3K/Akt/mTOR signaling pathways in lung cancer. Mol. Ther. Oncol. 3:16018. doi: 10.1038/mto.2016.18

Jing, X., Cheng, W., Wang, S., Li, P., and He, L. (2016). Resveratrol induces cell cycle arrest in human gastric cancer MGC803 cells via the PTEN-regulated PI3K/Akt signaling pathway. Oncol. Rep. 35, 472-478. doi: 10.3892/or.2015. 4384

Johnson, S. M., Wang, X., and Evers, B. M. (2011). Triptolide inhibits proliferation and migration of colon cancer cells by inhibition of cell cycle regulators and cytokine receptors. J. Surg. Res. 168, 197-205. doi: 10.1016/j.jss.2009.07.002

Jung, S. K., and Jeong, C. H. (2016). Dehydroglyasperin D inhibits the proliferation of HT-29 human colorectal cancer cells through direct interaction with phosphatidylinositol 3-kinase. J. Cancer Prev. 21:26. doi: 10.15430/JCP.2016.21.1.26

Kadioglu, O., Seo, E., and Efferth, T. (2013). Targeting angiogenesis by phytochemicals. Med. Aromat. Plants 2, 1-8. doi: 10.4172/2167-0412.1000134

Kar, S., Palit, S., Ball, W. B., and Das, P. K. (2012). Carnosic acid modulates $\mathrm{Akt} / \mathrm{IKK} / \mathrm{NF}-\mathrm{\kappa B}$ signaling by PP2A and induces intrinsic and extrinsic pathway mediated apoptosis in human prostate carcinoma PC-3 cells. Apoptosis 17, 735-747. doi: 10.1007/s10495-012-0715-4

Karki, R., Malireddi, R. K. S., Zhu, Q., and Kanneganti, T. D. (2017). NLRC3 regulates cellular proliferation and apoptosis to attenuate the development of colorectal cancer. Cell Cycle 16, 1243-1251. doi: 10.1080/15384101.2017.1317414

Karki, R., Man, S. M., Malireddi, R. K., Kesavardhana, S., Zhu, Q., Burton, A. R., et al. (2016). NLRC3 is an inhibitory sensor of PI3K-mTOR pathways in cancer. Nature 540, 583-587. doi: 10.1038/nature20597

Kershaw, J., and Kim, K. H. (2017). The therapeutic potential of piceatannol, a natural stilbene, in metabolic diseases: a review. J. Med. Food 20, 427-438. doi: 10.1089/jmf.2017.3916

Keum, Y. S., Han, S. S., Chun, K. S., Park, K. K., Park, J. H., Lee, S. $\mathrm{K}$., et al. (2003). Inhibitory effects of the ginsenoside $\mathrm{Rg} 3$ on phorbol 
ester-induced cyclooxygenase-2 expression, NF- $\mathrm{B}$ activation and tumor promotion. Mutat. Res. Fundam. Mol. Mech. Mutagenesis 523, 75-85. doi: 10.1016/S0027-5107(02)00323-8

Khan, N., Afaq, F., Khusro, F. H., Mustafa Adhami, V., Suh, Y., and Mukhtar, H. (2012). Dual inhibition of phosphatidylinositol 3-kinase/Akt and mammalian target of rapamycin signaling in human nonsmall cell lung cancer cells by a dietary flavonoid fisetin. Int. J. Cancer 130, 1695-1705. doi: 10.1002/ijc. 26178

Khan, N., Syed, D. N., Ahmad, N., and Mukhtar, H. (2013). Fisetin: a dietary antioxidant for health promotion. Antioxid. Redox Signal. 19, 151-162. doi: 10.1089/ars.2012.4901

Kim, H. Y., Jung, S. K., Byun, S., Son, J. E., Oh, M. H., Lee, J., et al. (2013). Raf and PI3K are the molecular targets for the anti-metastatic effect of luteolin. Phytother. Res. 27, 1481-1488. doi: 10.1002/ptr.4888

Kim, J. H., Liu, L., Lee, S. O., Kim, Y. T., You, K. R., and Kim, D. G. (2005). Susceptibility of cholangiocarcinoma cells to parthenolide-induced apoptosis. Cancer Res. 65, 6312-6320. doi: 10.1158/0008-5472.CAN-04-4193

Kim, M. J., Lee, T. H., Kim, S. H., Choi, Y. J., Heo, J., and Kim, Y. H. (2010). Triptolide inactivates Akt and induces caspase-dependent death in cervical cancer cells via the mitochondrial pathway. Int. J. Oncol. 37:1177. doi: 10.3892/ijo_00000769

Kim, S. H., Kang, J. G., Kim, C. S., Ihm, S. H., Choi, M. G., Yoo, H. J., et al. (2016). Synergistic cytotoxicity of BIIB021 with triptolide through suppression of PI3K/Akt/mTOR and NF-кB signal pathways in thyroid carcinoma cells. Biomed. Pharmacother. 83, 22-32. doi: 10.1016/j.biopha.2016.06.014

Kim, S. J., Kim, H. J., Kim, H. R., Lee, S. H., Cho, S. D., Choi, C. S., et al. (2012). Antitumor actions of baicalein and wogonin in HT-29 human colorectal cancer cells. Mol. Med. Rep. 6, 1443-1449. doi: 10.3892/mmr.2012.1085

King, D., Yeomanson, D., and Bryant, H. E. (2015). PI3King the lock: targeting the PI3K/Akt/mTOR pathway as a novel therapeutic strategy in neuroblastoma. J. Pediatr. Hematol. Oncol. 37, 245-251. doi: 10.1097/MPH.0000000000 000329

Knight, D. W. (1995). Feverfew: chemistry and biological activity. Nat. Prod. Rep. 12, 271-276. doi: 10.1039/np9951200271

Ko, H. S., Lee, H. J., Kim, S. H., and Lee, E. O. (2012). Piceatannol suppresses breast cancer cell invasion through the inhibition of MMP-9: involvement of PI3K/Akt and NF-кB pathways. J. Agric. Food Chem. 60, 4083-4089. doi: $10.1021 /$ jf205171g

Koo, H. N., Jeong, H. J., Choi, I. Y., An, H. J., Moon, P. D., Kim, S. J., et al. (2007). Mountain grown ginseng induces apoptosis in HL-60 cells and its mechanism have little relation with TNF- $\alpha$ production. Am. J. Chinese Med. 35, 169-182. doi: 10.1142/S0192415X07004710

Kowshik, J., Giri, H., Kishore, T. K., Kesavan, R., Vankudavath, R. N., Reddy, G. B., et al. (2014). Ellagic acid inhibits VEGF/VEGFR2, PI3K/Akt and MAPK signaling cascades in the hamster cheek pouch carcinogenesis model. Anti Cancer Agents Med. Chem. 14, 1249-1260. doi: 10.2174/1871520614666140723114217

Kubota, N., Okada, S., Inada, T., Ohnishi, K., and Ohnishi, T. (2000). Wortmannin sensitizes human glioblastoma cell lines carrying mutant and wild type TP53 gene to radiation. Cancer Lett. 161, 141-147. doi: 10.1016/S0304-3835(00)00614-5

Kumar, D., Das, B., Sen, R., Kundu, P., Manna, A., Sarkar, A., et al. (2015). Andrographolide analogue induces apoptosis and autophagy mediated cell death in U937 cells by inhibition of PI3K/Akt/mTOR pathway. PLoS ONE 10:e0139657. doi: 10.1371/journal.pone.0139657

Kuo, P. L., Hsu, Y. L., and Cho, C. Y. (2006). Plumbagin induces G2$\mathrm{M}$ arrest and autophagy by inhibiting the Akt/mammalian target of rapamycin pathway in breast cancer cells. Mol. Cancer Ther. 5, 3209-3221. doi: 10.1158/1535-7163.MCT-06-0478

Kwon, J. K., Park, Y. S., Park, B. K., Kim, B. S., Kim, S. K., and Jung, J. Y. (2012). Resveratrol induces apoptosis through PI3K/Akt and p53 signal pathway in MDA-MB-231 breast cancer cells. Korean J. Food Sci. Technol. 44, 452-459. doi: 10.9721/KJFST.2012.44.4.452

Kwon, J. Y., Seo, S. G., Heo, Y. S., Yue, S., Cheng, J. X., Lee, K. W., et al. (2012). Piceatannol, natural polyphenolic stilbene, inhibits adipogenesis via modulation of mitotic clonal expansion and insulin receptor-dependent insulin signaling in early phase of differentiation. J. Biol. Chem. 287, 11566-11578. doi: 10.1074/jbc.M111.259721
Kwon, S. H., Hong, S. I., Kim, J. A., Jung, Y. H., Kim, S. Y., Kim, H. C., et al. (2011). The neuroprotective effects of Lonicera japonica THUNB. against hydrogen peroxide-induced apoptosis via phosphorylation of MAPKs and PI3K/Akt in SH-SY5Y cells. Food Chem. Toxicol. 49:1011-1019. doi: 10.1016/j.fct.2011.01.008

Laughner, E., Taghavi, P., Chiles, K., Mahon, P. C., and Semenza, G. L. (2001). HER2 (neu) signaling increases the rate of hypoxia-inducible factor $1 \alpha$ (HIF-1 $\alpha)$ synthesis: novel mechanism for HIF-1-mediated vascular endothelial growth factor expression. Mol. Cell. Biol. 21, 3995-4004. doi: 10.1128/MCB.21.12.3995-4004.2001

Lee, K. Y., Park, J. S., Jee, Y. K., and Rosen, G. D. (2002). Triptolide sensitizes lung cancer cells to TNF-related apoptosis-inducing ligand (TRAIL)-induced apoptosis by inhibition of NF-[kappa] B activation. Exp. Mol. Med. 34:462. doi: $10.1038 / \mathrm{emm} .2002 .64$

Lee, P. J., Camhi, S. L., Chin, B. Y., Alam, J., and Choi, A. M. (2000). AP-1 and STAT mediate hyperoxia-induced gene transcription of heme oxygenase-1. Am. J. Physiol. Lung Cell. Mol. Physiol. 279, L175-L182.

Lee, S. Y., Kim, G. T., Roh, S. H., Jin-Su, S. O. N. G., Hie-Joon, K. I. M., Soon-Sun, H. O. N. G., et al. (2009). Proteomic analysis of the anti-cancer effect of 20Sginsenoside Rg3 in human colon cancer cell lines. Biosci. Biotechnol. Biochem. 73, 811-816. doi: 10.1271/bbb.80637

Lee, Y. C., Lin, H. H., Hsu, C. H., Wang, C. J., Chiang, T. A., and Chen, J. H. (2010). Inhibitory effects of andrographolide on migration and invasion in human nonsmall cell lung cancer A549 cells via down-regulation of PI3K/Akt signaling pathway. Eur. J. Pharmacol. 632, 23-32. doi: 10.1016/j.ejphar.2010.01.009

Li, H., Fan, Y., Zhang, L., Liu, A., Tu, F., He, K., et al. (2016). Phenethyl isothiocyanate inhibits the migration and invasion of colon cancer SW480 cells via the inhibition of matrix metalloproteinase-9. Int. J. Clin. Exp. Med. 9, 2423-2429.

Li, H., Pan, G. F., Jiang, Z. Z., Yang, J., Sun, L. X., and Zhang, L. Y. (2015). Triptolide inhibits human breast cancer MCF-7 cell growth via downregulation of the ER $\alpha$-mediated signaling pathway. Acta Pharmacol. Sin. 36, 606. doi: 10.1038/aps.2014.162

Li, J., Cheung, H. Y., Zhang, Z., Chan, G. K., and Fong, W. F. (2007) Andrographolide induces cell cycle arrest at G2/M phase and cell death in HepG2 cells via alteration of reactive oxygen species. Eur. J. Pharmacol. 568, 31-44. doi: 10.1016/j.ejphar.2007.04.027

Li, J., Zhang, C., Jiang, H., and Cheng, J. (2015). Andrographolide inhibits hypoxia-inducible factor-1 through phosphatidylinositol 3-kinase/Akt pathway and suppresses breast cancer growth. Oncol. Targets. Ther. 8:427. doi: 10.2147/OTT.S76116

Li, M., Zhang, X., Zhou, W. J., Chen, Y. H., Liu, H., Liu, L., et al. (2013). Hsp90 inhibitor BIIB021 enhances triptolide-induced apoptosis of human T-cell acute lymphoblastic leukemia cells in vitro mainly by disrupting p53-MDM2 balance. Acta Pharmacol. Sin. 34:1545. doi: 10.1038/aps.2013.124

Li, T., Wong, V. K. W., Yi, X. Q., Wong, Y. F., Zhou, H., and Liu, L. (2010). Matrine induces cell anergy in human Jurkat $\mathrm{T}$ cells through modulation of mitogenactivated protein kinases and nuclear factor of activated T-cells signaling with concomitant up-regulation of anergy-associated genes expression. Biol. Pharmaceut. Bull. 33, 40-46. doi: 10.1248/bpb.33.40

Li, X., Chu, W., Liu, J., Xue, X., Lu, Y., Shan, H., et al. (2009). Antiarrhythmic properties of long-term treatment with matrine in arrhythmic rat induced by coronary ligation. Biol. Pharmaceut. Bull. 32, 1521-1526. doi: $10.1248 / \mathrm{bpb} .32 .1521$

Li, Y. C., He, S. M., He, Z. X., Li, M., Yang, Y., Pang, J. X., et al. (2014). Plumbagin induces apoptotic and autophagic cell death through inhibition of the PI3K/Akt/mTOR pathway in human non-small cell lung cancer cells. Cancer Lett. 344, 239-259. doi: 10.1016/j.canlet.2013. 11.001

Li, Y., Zhang, P., Qiu, F., Chen, L., Miao, C., Li, J., et al. (2012). Inactivation of PI3K/Akt signaling mediates proliferation inhibition and G2/M phase arrest induced by andrographolide in human glioblastoma cells. Life Sci. 90, 962-967. doi: 10.1016/j.lfs.2012.04.044

Lijuan, W., Xiaoying, J., Zipei, C., and Wenlu, L. (2016). Evodiamine induces extrinsic and intrinsic apoptosis of ovarian cancer cells via the mitogen-activated protein kinase/phosphatidylinositol-3-kinase/protein kinase B signaling pathways. J. Tradit. Chinese Med. 36, 353-359. doi: 10.1016/S0254-6272(16)30049-8 
Lin, S., Li, J., Zhou, W., Qian, W., Wang, B., and Chen, Z. (2014). BIIB021, an Hsp90 inhibitor, effectively kills a myelodysplastic syndrome cell line via the activation of caspases and inhibition of PI3K/Akt and NF- $\kappa$ B pathway proteins. Exp. Ther. Med. 7, 1539-1544. doi: 10.3892/etm.2014.1651

Liou, K. T., Shen, Y. C., Chen, C. F., Tsao, C. M., and Tsai, S. K. (2003). The anti-inflammatory effect of honokiol on neutrophils: mechanisms in the inhibition of reactive oxygen species production. Eur. J. Pharmacol. 475, 19-27. doi: 10.1016/S0014-2999(03)02121-6

Liu, J. W., Cai, M. X., Xin, Y., Wu, Q. S., Ma, J., Yang, P., et al. (2010). Parthenolide induces proliferation inhibition and apoptosis of pancreatic cancer cells in vitro. J. Exp. Clin. Cancer Res. 29:108. doi: 10.1186/1756-9966-29-108

Liu, P., Cheng, H., Roberts, T. M., and Zhao, J. J. (2009). Targeting the phosphoinositide 3-kinase pathway in cancer. Nat. Rev. Drug Discov. 8, 627-644. doi: 10.1038/nrd2926

Liu, S., Wang, X. J., Liu, Y., and Cui, Y. F. (2013). PI3K/Akt/mTOR signaling is involved in (-)-epigallocatechin-3-gallate-induced apoptosis of human pancreatic carcinoma cells. Am. J. Chinese Med. 41, 629-642. doi: 10.1142/S0192415X13500444

Liu, Y., Bi, T., Dai, W., Wang, G., Qian, L., Gao, Q., et al. (2016). Effects of oxymatrine on the proliferation and apoptosis of human hepatoma carcinoma cells. Technol. Cancer Res. Treat. 15, 487-497. doi: 10.1177/1533034615587616

Li-Weber, M. (2009). New therapeutic aspects of flavones: the anticancer properties of Scutellaria and its main active constituents Wogonin, Baicalein and Baicalin. Cancer Treat. Rev. 35, 57-68. doi: 10.1016/j.ctrv.2008.09.005

Lo, Y. C., Che-Ming, T., Chieh-Fu, C., Chien-Chih, C., and Chuang-Ye, H. (1994). Magnolol and honokiol isolated from Magnolia officinalis protect rat heart mitochondria against lipid peroxidation. Biochem. Pharmacol. 47, 549-553. doi: 10.1016/0006-2952(94)90187-2

Long, Y., Lin, X. T., Zeng, K. L., and Zhang, L. (2004). Efficacy of intramuscular matrine in the treatment of chronic hepatitis B. HBPD INT 3, 69-72.

LoPiccolo, J., Blumenthal, G. M., Bernstein, W. B., and Dennis, P. A. (2008). Targeting the PI3K/Akt/mTOR pathway: effective combinations and clinical considerations. Drug Resist. Updates 11, 32-50. doi: 10.1016/j.drup.2007.11.003

Luo, J., Manning, B. D., and Cantley, L. C. (2003). Targeting the PI3K-Akt pathway in human cancer: rationale and promise. Cancer Cell 4, 257-262. doi: 10.1016/S1535-6108(03)00248-4

Lv, Z., Zhao, D., Liu, R., Guo, J., Lin, Y., and Zhang, M. (2016). Evodiamine inhibits proliferation of human papillary thyroid cancer cell line K1 by regulating of PI3K/Akt signaling pathway. Int. J. Clin. Exp. Med. 9, $15216-15225$.

Mann, J. (2002). Natural products in cancer chemotherapy: past, present and future. Nat. Rev. Cancer 2:143. doi: 10.1038/nrc723

Manzo, S. G., Zhou, Z. L., Wang, Y. Q., Marinello, J., He, J. X., Li, Y. C., et al. (2012). Natural product triptolide mediates cancer cell death by triggering CDK7dependent degradation of RNA polymerase II. Cancer Res. 72, 5363-5373. doi: 10.1158/0008-5472.CAN-12-1006

Mao, C. G., Tao, Z. Z., Chen, Z., Chen, C., Chen, S. M., and Wan, L. J. (2014). Indole-3-carbinol inhibits nasopharyngeal carcinoma cell growth in vivo and in vitro through inhibition of the PI3K/Akt pathway. Exp. Ther. Med. 8, 207-212. doi: $10.3892 /$ etm.2014.1696

Martin, G. S. (2003). Cell signaling and cancer. Cancer Cell 4, 167-174. doi: 10.1016/S1535-6108(03)00216-2

Massacesi, C., Di Tomaso, E., Urban, P., Germa, C., Quadt, C., Trandafir, L., et al. (2016). PI3K inhibitors as new cancer therapeutics: implications for clinical trial design. Oncol. Targets. Ther. 9, 203-210. doi: 10.2147/OTT. S89967

Maurya, A. K., and Vinayak, M. (2016). PI-103 and quercetin attenuate PI3K-Akt signalling pathway in T-cell lymphoma exposed to hydrogen peroxide. PLoS ONE 11:e0160686. doi: 10.1371/journal.pone.0160686

Meybodi, N. M., Mortazavian, A. M., Monfared, A. B., Sohrabvandi, S., and Meybodi, F. A. (2017). Phytochemicals in cancer prevention: a review of the evidence. Iran. J. Cancer Prev. 10:e7219. doi: 10.17795/ijcp-7219

Michaud, D. S., Feskanich, D., Rimm, E. B., Colditz, G. A., Speizer, F. E., Willett, W. C., et al. (2000). Intake of specific carotenoids and risk of lung cancer in 2 prospective US cohorts. Am. J. Clin. Nutr. 72, 990-997.

Minami, M., Nishio, K., Ajioka, Y., Kyushima, H., Shigeki, K., Kinjo, K., et al. (2009). Identification of Curcuma plants and curcumin content level by DNA polymorphisms in the trnS-trnfM intergenic spacer in chloroplast DNA. J. Nat. Med. 63, 75-79. doi: 10.1007/s11418-008-0283-7

Miyata, Y., Sato, T., and Ito, A. (2005). Triptolide, a diterpenoid triepoxide, induces antitumor proliferation via activation of c-Jun $\mathrm{NH}$ 2-terminal kinase 1 by decreasing phosphatidylinositol 3-kinase activity in human tumor cells. Biochem. Biophys. Res. Commun. 336, 1081-1086. doi: 10.1016/j.bbrc.2005.08.247

Morgan, M. J., and Liu, Z. G. (2011). Crosstalk of reactive oxygen species and NF-KB signaling. Cell Res. 21:103. doi: 10.1038/cr.2010.178

Morgan, T. M., Koreckij, T. D., and Corey, E. (2009). Targeted therapy for advanced prostate cancer: inhibition of the PI3K/Akt/mTOR pathway. Curr. Cancer Drug Targets 9, 237-249. doi: 10.2174/156800909787580999

Mu, G. G., Zhang, L. L., Li, H. Y., Liao, Y., and Yu, H. G. (2015). Thymoquinone pretreatment overcomes the insensitivity and potentiates the antitumor effect of gemcitabine through abrogation of Notch1, PI3K/Akt/mTOR regulated signaling pathways in pancreatic cancer. Dig. Dis. Sci. 60, 1067-1080. doi: 10.1007/s10620-014-3394-x

Nahta, R., Yu, D., Hung, M. C., Hortobagyi, G. N., and Esteva, F. J. (2006). Mechanisms of disease: understanding resistance to HER2-targeted therapy in human breast cancer. Nat. Rev. Clin. Oncol. 3:269. doi: 10.1038/ncponc0509

Nakanishi, K., Sakamoto, M., Yamasaki, S., Todo, S., and Hirohashi, S. (2005). Akt phosphorylation is a risk factor for early disease recurrence and poor prognosis in hepatocellular carcinoma. Cancer 103, 307-312. doi: 10.1002/cncr.20774

Nomura, M., Kaji, A., He, Z., Ma, W. Y., Miyamoto, K. I., Yang, C. S., et al. (2001). Inhibitory mechanisms of tea polyphenols on the ultraviolet Bactivated phosphatidylinositol 3-kinase-dependent pathway. J. Biol. Chem. 276, 46624-46631. doi: 10.1074/jbc.M107897200

Normanno, N., Di Maio, M., De Maio, E., De Luca, A., de Matteis, A., Giordano, A., et al. (2005). Mechanisms of endocrine resistance and novel therapeutic strategies in breast cancer. Endocr. Relat. Cancer 12, 721-747. doi: $10.1677 /$ erc. 1.00857

Okkenhaug, K., and Vanhaesebroeck, B. (2003). PI3K in lymphocyte development, differentiation and activation. Nat. Rev. Immunol. 3, 317-330. doi: $10.1038 /$ nri1056

Onyango, I. G., Bennett, J. P., and Tuttle, J. B. (2005). Endogenous oxidative stress in sporadic Alzheimer's disease neuronal cybrids reduces viability by increasing apoptosis through pro-death signaling pathways and is mimicked by oxidant exposure of control cybrids. Neurobiol. Dis. 19, 312-322. doi: 10.1016/j.nbd.2005.01.026

Osaki, M., Oshimura, M. A., and Ito, H. (2004). PI3K-Akt pathway: its functions and alterations in human cancer. Apoptosis 9, 667-676. doi: 10.1023/B:APPT.0000045801.15585.dd

Padhye, S., Dandawate, P., Yusufi, M., Ahmad, A., and Sarkar, F. H. (2012). Perspectives on medicinal properties of plumbagin and its analogs. Med. Res. Rev. 32, 1131-1158. doi: 10.1002/med.20235

Pan, S. T., Qin, Y., Zhou, Z. W., He, Z. X., Zhang, X., Yang, T., et al. (2015). Plumbagin induces $\mathrm{G}_{2} / \mathrm{M}$ arrest, apoptosis, and autophagy via p38 MAPKand PI3K/Akt/mTOR-mediated pathways in human tongue squamous cell carcinoma cells. Drug Des. Devel. Ther. 9, 1601-1626. doi: 10.2147/DDDT. S76057

Park, Y. J., Wen, J., Bang, S., Park, S. W., and Song, S. Y. (2006). [6]-Gingerol induces cell cycle arrest and cell death of mutant p53-expressing pancreatic cancer cells. Yonsei Med. J. 47, 688-697. doi: 10.3349/ymj.2006.47.5.688

Patel, S. (2013). Exploring novel therapeutic targets in GIST: focus on the PI3K/Akt/mTOR pathway. Curr. Oncol. Rep. 15, 386-395. doi: 10.1007/s11912-013-0316-6

Pawlik, A., Wiczk, A., Kaczynska, A., Antosiewicz, J., and Herman-Antosiewicz, A. (2013). Sulforaphane inhibits growth of phenotypically different breast cancer cells. Eur. J. Nutr. 52, 1949-1958. doi: 10.1007/s00394-013-0499-5

Pfeifer, B. L., and Fahrendorf, T. (2015). Indole-3-carbinol: a glucosinolate derivative from cruciferous vegetables for prevention and complementary treatment of breast cancer. German J. Oncol. 47, 20-27.

Pons-Tostivint, E., Thibault, B., and Guillermet-Guibert, J. (2017). Targeting PI3K signaling in combination cancer therapy. Trends Cancer 3, 454-469. doi: 10.1016/j.trecan.2017.04.002

Qian, X., Song, J. M., Melkamu, T., Upadhyaya, P., and Kassie, F. (2013). Chemoprevention of lung tumorigenesis by intranasally 
administered diindolylmethane in A/J mice. Carcinogenesis 34, 841-849. doi: $10.1093 /$ carcin/bgs390

Rachid, O., and Alkhalaf, M. (2006). Resveratrol regulation of PI3K-Akt signalling pathway genes in MDA-MB-231 breast cancer cells. Cancer Genomics Proteomics 3, 383-388.

Rajput, S., Kumar, B. P., Sarkar, S., Das, S., Azab, B., Santhekadur, P. K., et al. (2013). Targeted apoptotic effects of thymoquinone and tamoxifen on XIAP mediated Akt regulation in breast cancer. PLoS ONE 8:e61342. doi: 10.1371/journal.pone.0061342

Reddy, L., Odhav, B., and Bhoola, K. D. (2003). Natural products for cancer prevention: a global perspective. Pharmacol. Ther. 99, 1-13. doi: 10.1016/S0163-7258(03)00042-1

Ruela-de-Sousa, R. R., Fuhler, G. M., Blom, N., Ferreira, C. V., Aoyama, H., and Peppelenbosch, M. P. (2010). Cytotoxicity of apigenin on leukemia cell lines: implications for prevention and therapy. Cell Death Dis. 1:e19. doi: $10.1038 /$ cddis.2009.18

Ryu, M. J., and Chung, H. S. (2015). [10]-Gingerol induces mitochondrial apoptosis through activation of MAPK pathway in HCT116 human colon cancer cells. In Vitro Cell. Dev. Biol. Anim. 51, 92-101. doi: 10.1007/s11626-014-9806-6

Saini, K. S., Loi, S., de Azambuja, E., Metzger-Filho, O., Saini, M. L., Ignatiadis, M., et al. (2013). Targeting the PI3K/Akt/mTOR and Raf/MEK/ERK pathways in the treatment of breast cancer. Cancer Treat. Rev. 39, 935-946. doi: 10.1016/j.ctrv.2013.03.009

Samuels, Y., Wang, Z., Bardelli, A., Silliman, N., Ptak, J., Szabo, S., et al. (2004). High frequency of mutations of the PIK3CA gene in human cancers. Science 304, 554-554. doi: 10.1126/science.1096502

Sandler, A. D., Knudsen, M. W., Brown, T. T., and Christian, R. M. (1997). Neurodevelopmental dysfunction among nonreferred children with idiopathic megalencephaly. J. Pediatr. 131, 320-324.

Shao, H., Ma, J., Guo, T., and Hu, R. (2014). Triptolide induces apoptosis of breast cancer cells via a mechanism associated with the $\mathrm{Wnt} / \beta$-catenin catenin signaling pathway. Exp. Ther. Med. 8, 505-508. doi: 10.3892/etm.2014.1729

Shehzad, A., Lee, J., and Lee, Y. S. (2013). Curcumin in various cancers. Biofactors 39, 56-68. doi: 10.1002/biof.1068

Shu, B., Duan, W., Yao, J., Huang, J., Jiang, Z., and Zhang, L. (2009). Caspase 3 is involved in the apoptosis induced by triptolide in HK-2 cells. Toxicol. In Vitro 23, 598-602. doi: 10.1016/j.tiv.2009.01.021

Shukla, S., and Gupta, S. (2007). Apigenin-induced cell cycle arrest is mediated by modulation of MAPK, PI3K-Akt, and loss of cyclin D1 associated retinoblastoma dephosphorylation in human prostate cancer cells. Cell Cycle 6, 1102-1114. doi: 10.4161/cc.6.9.4146

Singh, R. K., Dorf, L., DeMartino, A., Illenye, S., Koto, K., Currier, E. A., et al. (2011). Oral RKS262 reduces tumor burden in a neuroblastoma xenograft animal model and mediates cytotoxicity through SAPK/JNK and ROS activation in vitro. Cancer Biol. Ther. 11, 1036-1045. doi: 10.4161/cbt.11.12.15706

Slomovitz, B. M., and Coleman, R. L. (2012). The PI3K/Akt/mTOR pathway as a therapeutic target in endometrial cancer. Clin. Cancer Res. 18, 5856-5864. doi: 10.1158/1078-0432.CCR-12-0662

Song, N. R., Hwang, M. K., Heo, Y. S., Lee, K. W., and Lee, H. J. (2013). Piceatannol suppresses the metastatic potential of MCF10A human breast epithelial cells harboring mutated H-ras by inhibiting MMP-2 expression. Int. J. Mol. Med. 32, 775-784. doi: 10.3892/ijmm.2013.1449

Stathis, A., and Moore, M. J. (2010). Advanced pancreatic carcinoma: current treatment and future challenges. Nat. Rev. Clin. Oncol. 7:163. doi: 10.1038/nrclinonc.2009.236

Sun, Y., Clair, D. K. S., Xu, Y., Crooks, P. A., and Clair, W. H. S. (2010). A NADPH oxidase-dependent redox signaling pathway mediates the selective radiosensitization effect of parthenolide in prostate cancer cells. Cancer Res. 70, 2880-2890. doi: 10.1158/0008-5472.CAN-09-4572

Sun, Z., Wang, Z., Liu, X., and Wang, D. (2015). New development of inhibitors targeting the $\mathrm{PI} 3 \mathrm{~K} / \mathrm{AKT} / \mathrm{mTOR}$ pathway in personalized treatment of non-small-cell lung cancer. Anticancer. Drugs 26, 1-14. doi: 10.1097/CAD.0000000000000172

Treins, C., Giorgetti-Peraldi, S., Murdaca, J., Semenza, G. L., and Van Obberghen, E. (2002). Insulin stimulates hypoxia-inducible factor 1 through a phosphatidylinositol 3-kinase/target of rapamycin-dependent signaling pathway. J. Biol. Chem. 277, 27975-27981. doi: 10.1074/jbc.M204152200

Wang, J. H., Nao, J. F., Zhang, M., and He, P. (2014). 20 (s)-ginsenoside Rg3 promotes apoptosis in human ovarian cancer HO-8910 cells through PI3K/Akt and XIAP pathways. Tumor Biol. 35, 11985-11994. doi: 10.1007/s13277-014-2497-5

Wang, T., Chen, F., Chen, Z., Wu, Y. F., Xu, X. L., Zheng, S., et al. (2004). Honokiol induces apoptosis through p53-independent pathway in human colorectal cell line RKO. World J. Gastroenterol. 10, 2205-2208. doi: 10.3748/wjg.v10.i15.2205

Wang, W., Zhao, Y., Rayburn, E. R., Hill, D. L., Wang, H., and Zhang, R. (2007). In vitro anti-cancer activity and structure-activity relationships of natural products isolated from fruits of Panax ginseng. Cancer Chemother. Pharmacol. 59, 589-601. doi: 10.1007/s00280-006-0300-Z

Wang, Z., Wu, L., Tong, S., Hu, X., Zu, X., Li, Y., et al. (2016). Resveratrol suppresses the epithelial-to-mesenchymal transition in PC-3 cells by downregulating the PI3K/Akt signaling pathway. Anim. Cells Syst. 20, 77-85. doi: 10.1080/19768354.2016.1150344

Way, T. D., Kao, M. C., and Lin, J. K. (2004). Apigenin induces apoptosis through proteasomal degradation of HER2/neu in HER2/neu-overexpressing breast cancer cells via the phosphatidylinositol 3-kinase/Akt-dependent pathway. J. Biol. Chem. 279, 4479-4489. doi: 10.1074/jbc.M305529200

Weng, C. J., Chou, C. P., Ho, C. T., and Yen, G. C. (2012). Molecular mechanism inhibiting human hepatocarcinoma cell invasion by 6-shogaol and 6-gingerol. Mol. Nutr. Food Res. 56, 1304-1314. doi: 10.1002/mnfr.201200173

Woo, C. C., Kumar, A. P., Sethi, G., and Tan, K. H. B. (2012). Thymoquinone: potential cure for inflammatory disorders and cancer. Biochem. Pharmacol. 83, 443-451. doi: 10.1016/j.bcp.2011.09.029

Workman, P., Clarke, P. A., Guillard, S., and Raynaud, F. I. (2006). Drugging the PI3 kinome. Nat. Biotechnol. 24, 794-795. doi: 10.1038/nbt0706-794

Wu, H., Dai, X., and Wang, E. (2016). Plumbagin inhibits cell proliferation and promotes apoptosis in multiple myeloma cells through inhibition of the PI3K/Akt-mTOR pathway. Oncol. Lett. 12, 3614-3618. doi: $10.3892 / \mathrm{ol} .2016 .5048$

Xiang, T., Fang, Y., and Wang, S. X. (2014). Quercetin suppresses HeLa cells by blocking PI3K/Akt pathway. J. Huazhong Univ. Sci. Technol. 34, 740-744. doi: 10.1007/s11596-014-1345-6

Xu, B., Guo, X., Mathew, S., Armesilla, A. L., Cassidy, J., Darling, J. L., et al. (2010). Triptolide simultaneously induces reactive oxygen species, inhibits NF$\kappa \mathrm{B}$ activity and sensitizes 5-fluorouracil in colorectal cancer cell lines. Cancer Lett. 291, 200-208. doi: 10.1016/j.canlet.2009.10.013

Xu, D., Ma, Y., Zhao, B., Li, S., Zhang, Y., Pan, S., et al. (2014). Thymoquinone induces $\mathrm{G} 2 / \mathrm{M}$ arrest, inactivates PI3K/Akt and nuclear factor- $\mathrm{KB}$ pathways in human cholangiocarcinomas both in vitro and in vivo. Oncol. Rep. 31, 2063-2070. doi: 10.3892/or.2014.3059

Yang, M., Wang, H., Zhou, M., Liu, W., Kuang, P., Liang, H., et al. (2016). The natural compound sulforaphene, as a novel anticancer reagent, targeting PI3K-Akt signaling pathway in lung cancer. Oncotarget 7:76656. doi: 10.18632 /oncotarget.12307

Yang, S. E., Hsieh, M. T., Tsai, T. H., and Hsu, S. L. (2002). Down-modulation of $\mathrm{Bcl}-\mathrm{x} \mathrm{L}$, release of cytochrome $\mathrm{c}$ and sequential activation of caspases during honokiol-induced apoptosis in human squamous lung cancer $\mathrm{CH} 27$ cells. Biochem. Pharmacol. 63, 1641-1651. doi: 10.1016/S0006-2952(02)00894-8

Yang, X. L., Lin, F. J., Guo, Y. J., Shao, Z. M., and Ou, Z. L. (2014). Gemcitabine resistance in breast cancer cells regulated by PI3K/Akt-mediated cellular proliferation exerts negative feedback via the MEK/MAPK and mTOR pathways. Oncol. Targets Ther. 7, 1033-1042. doi: 10.2147/OTT.S63145

Yap, T. A., Bjerke, L., Clarke, P. A., and Workman, P. (2015). Drugging PI3K in cancer: refining targets and therapeutic strategies. Curr. Opin. Pharmacol. 23, 98-107. doi: 10.1016/j.coph.2015.05.016

Yap, T. A., Garrett, M. D., Walton, M. I., Raynaud, F., de Bono, J. S., and Workman, P. (2008). Targeting the PI $3 \mathrm{~K}-\mathrm{Akt}-\mathrm{mTOR}$ pathway: progress, pitfalls, and promises. Curr. Opin. Pharmacol. 8, 393-412. doi: 10.1016/j.coph.2008.08.004

Yi, Y. W., Kang, H. J., Kim, H. J., Hwang, J. S., Wang, A., and Bae, I. (2013). Inhibition of constitutively activated phosphoinositide 3-kinase/Akt pathway enhances antitumor activity of chemotherapeutic agents in breast cancer susceptibility gene 1-defective breast cancer cells. Mol. Carcinog. 52, 667-675. doi: $10.1002 / m c .21905$ 
Yong, J., Wu, X., and Lu, C. (2015). Anticancer advances of matrine and its derivatives. Curr. Pharm. Des. 21, 3673-3680. doi: 10.2174/1381612821666150122123748

Yu, S. M., and Kim, S. J. (2013). Thymoquinone-induced reactive oxygen species causes apoptosis of chondrocytes via PI3K/Akt and p38kinase pathway. Exp. Biol. Med. 238, 811-820. doi: 10.1177/1535370213492685

Zanotto-Filho, A., Delgado-Cañedo, A., Schröder, R., Becker, M., Klamt, F., and Moreira, J. C. F. (2010). The pharmacological NFкB inhibitors BAY117082 and MG132 induce cell arrest and apoptosis in leukemia cells through ROS-mitochondria pathway activation. Cancer Lett. 288, 192-203. doi: 10.1016/j.canlet.2009.06.038

Zhang, F., Thakur, K., Hu, F., Zhang, J. G., and Wei, Z. J. (2017). 10-Gingerol, a phytochemical derivative from "tongling white ginger", inhibits cervical cancer: insights into the molecular mechanism and inhibitory targets. J. Agric. Food Chem. 65, 2089-2099. doi: 10.1021/acs.jafc.7b00095

Zhang, J. P., Zhang, M., Zhou, J. P., Liu, F. T., Zhou, B., Xie, W. F., et al. (2001). Antifibrotic effects of matrine on in vitro and in vivo models of liver fibrosis in rats. Acta Pharmacol. Sin. 22, 183-186.

Zhang, M., Liu, L. P., Chen, Y., Tian, X. Y., Qin, J., Wang, D., et al. (2013). Wogonin induces apoptosis in RPMI 8226, a human myeloma cell line, by downregulating phospho-Akt and overexpressing Bax. Life Sci. 92, 55-62. doi: 10.1016/j.lfs.2012.10.023

Zhang, S., Ong, C. N., and Shen, H. M. (2004). Critical roles of intracellular thiols and calcium in parthenolide-induced apoptosis in human colorectal cancer cells. Cancer Lett. 208, 143-153. doi: 10.1016/j.canlet.2003.11.028

Zhang, X., Chen, S., and Wang, Y. (2007). Honokiol up-regulates prostacyclin synthease protein expression and inhibits endothelial cell apoptosis. Eur. J. Pharmacol. 554, 1-7. doi: 10.1016/j.ejphar.2006.09.065

Zhang, X., Zhu, Y., Duan, W., Feng, C., and He, X. (2015). Allicin induces apoptosis of the MGC-803 human gastric carcinoma cell line through the p38 mitogen-activated protein kinase/caspase-3 signaling pathway. Mol. Med. Rep. 11, 2755-2760. doi: 10.3892/mmr.2014.3109
Zhao, K., Song, X., Huang, Y., Yao, J., Zhou, M., Li, Z., et al. (2014). Wogonin inhibits LPS-induced tumor angiogenesis via suppressing PI3K/Akt/NFкB signaling. Eur. J. Pharmacol. 737, 57-69. doi: 10.1016/j.ejphar.2014. 05.011

Zhong, Y.-Y., Chen, H.-P., Tan, B.-Z., Yu, H.-H., and Huang, X.-S. (2013). Triptolide avoids cisplatin resistance and induces apoptosis via the reactive oxygen species/nuclear factor-кB pathway in SKOV3PT platinum-resistant human ovarian cancer cells. Oncol. Lett. 6, 1084-1092. doi: 10.3892/ol.2013. 1524

Zhou, Z. W., Li, X. X., He, Z. X., Pan, S. T., Yang, Y., Zhang, X., et al. (2015). Induction of apoptosis and autophagy via sirtuin1-and PI3K/Akt/mTORmediated pathways by plumbagin in human prostate cancer cells. Drug Des. Devel. Ther. 9:1511. doi: 10.2147/DDDT.S75976

Zhu, W., He, S., Li, Y., Qiu, P., Shu, M., Ou, Y., et al. (2010). Antiangiogenic activity of triptolide in anaplastic thyroid carcinoma is mediated by targeting vascular endothelial and tumor cells. Vascul. Pharmacol. 52, 46-54. doi: 10.1016/j.vph.2009.10.006

Ziaei, S., and Halaby, R. (2016). Immunosuppressive, anti-inflammatory and anti-cancer properties of triptolide: a mini review. Avicen. J. Phytomed. $6: 149$.

Conflict of Interest Statement: The authors declare that the research was conducted in the absence of any commercial or financial relationships that could be construed as a potential conflict of interest.

Copyright (c) 2017 Suvarna, Murahari, Khan, Chaubey and Sangave. This is an open-access article distributed under the terms of the Creative Commons Attribution License (CC BY). The use, distribution or reproduction in other forums is permitted, provided the original author(s) or licensor are credited and that the original publication in this journal is cited, in accordance with accepted academic practice. No use, distribution or reproduction is permitted which does not comply with these terms. 